\title{
Islands of Resilience: The history of the German strong verbs from a systemic point of view*
}

\author{
Robert Mailhammer
}

\begin{abstract}
Existing accounts of the German strong verbs show notable confusion about their historical development and remarkable diversity with regard to their systemic conceptualisation. Using a principal parts approach, this paper brings out the drastic changes the system of the Germanic strong verbs has undergone since its genesis. In particular, it is shown that the loss of the paradigmatic connection between the phonological root structure of a verb and its ablaut pattern is the key alteration that transformed the strong verbs from a highly homogenous and learner-friendly system to a complicated array of inflection classes whose predictability is no longer based on the citation form stored in the mental lexicon. However, this paper also reveals that it is exactly the remnants of the old system that keep the German strong verbs together as a group and even ensure a limited degree of productivity. The conclusions drawn for a synchronic representation are that the traditional concept of inflection classes, based on the phonological root structure, may be of more value than generally believed and that the conceptualisation of the paradigms of the strong verbs involving stem forms with different ablaut grades as principal parts is supported from the diachronic as well as from the synchronic point of view.
\end{abstract}

Keywords Modern German - strong verbs - principal parts - Minimal Generalisation Hypothesis word and paradigm morphology

\section{Introduction}

Grammars of Modern Standard German have had difficulties in coming to grips with the group of socalled strong verbs. This may be gathered from the various diverging descriptions in the literature, ranging from traditional categorisations according to ablaut patterns (e.g. Duden 1998) to analyses denying the strong verbs a special group status altogether (e.g. Augst 1975 and Eisenberg 2004). In between these more extreme positions, accounts from past and present, such as Kern \& Zutt (1977), Hempen (1988) and Duden (2005), have used the distribution of ablaut grades across the paradigm to classify the strong verbs of Modern Standard German. In a bid to present a more flexible analysis in line with natural morphology (e.g. Wurzel 1989), Bittner (1996) proposes a continuum of conjugational classes, advancing properties that distinguish prototypical strong from prototypical weak verbs (see also Köpcke 1998). ${ }^{1}$

Alongside these more theoretical approaches, language learner-orientated grammars have either opted to treat the strong verbs simply as irregular (e.g. Dreyer \& Schmitt 2002) - just like their Modern English counterparts - or have attempted to find ways of using implicational relations in order

\footnotetext{
* This paper was inspired by a paper presented by Gregory Stump on the $12^{\text {th }}$ Morphology Meeting in Budapest in 2006. I would like to thank Greg Stump and Raphael Finkel for their comments on a draft version of the paper and their prompt help with their computer program. Thanks also go to Adam Albright, Eric Anchimbe, Jennifer Hay, Daniel Hole, Theo Vennemann and an anonymous reviewer for suggesting valuable improvements. All remaining errors are, of course, my own.

${ }^{1}$ Wiese (forthc.) presents an insightful analysis of the German strong verbs, based on the framework of Integrational Linguistics, which in turn is based on the fundamental significance of the paradigm. However, as his model describes the regularities of ablaut from a purely synchronic point of view, it will not be discussed here. This paper applies a morphological model to an inflection system from a diachronic point of view, investigating the continuity of the ProtoGermanic ablaut system as represented in the Modern German strong verbs. Moreover, Wiese's account is neither designed nor suited to predict paradigmatic forms on the basis of the citation form but to unravel the systematicity of ablaut in the strong verbs of Modern German.
} 
to deduce the word forms of a paradigm from a limited set of stems that in turn can be predicted on the basis of the verb's citation form (e.g. Helbig \& Buscha 2005). Although the latter approach may seem reminiscent of the traditional system of ablaut classes, whose application is judged problematic in most recent accounts of Modern Standard German, there is in fact some evidence suggesting that the exploitation of implicational relations on a phonological basis is an important mnemonic strategy used by speakers to gauge the reliability of morphological rules. This does not only hold true for the acquisition process, but it also seems to be a significant part of the speakers' linguistic competence. Based on evidence from Italian, Albright (2002) shows that speakers use the phonological root structure of verbs to infer their conjugational patterns. He explains this with the Minimal Generalisation Hypothesis proposed by Pinker \& Prince (1988:130-134) and Albright \& Hayes (2002), which asserts that "if there are local subregularities in the data, learners will explore them to find the best possible analysis". In other words, if possible, learners form very specific, but very accurate rules even if they are only valid for a small proportion of the data. For instance, speakers may use the phonological environment - typically the root vowel and the root-final material - to form minimal generalisations for the acquisition and application of conjugational rules, such as that e.g. verbs with a CerC- structure follow a given pattern, whereas e.g. CelC-verbs follow a different pattern and so forth. Albright (2002) concludes that such more specific rules are more powerful than contextfree rules, because they are far more reliable.

One key argument for the validity of this interpretation is the fact that the subjects in Albright's test placed nonsense verbs into irregular conjugational classes on the basis of phonological similarity with irregular verbs and not into the regular class as expected. Conversely, with certain stem structures the regular conjugation was preferred, as there was a high number of regular models available. This explains why the normally unproductive strong verbs of Modern English and German enjoy a limited form of productivity in nonsense verbs in cases where the input matches the phonological stem structure of a strong verb that can then be used as a model (cf. Bybee \& Slobin 1982 for English, Clahsen et al. 1997 for German). Seen from the viewpoint of the minimal generalisation hypothesis, the strong verbs in this case simply follow a very specific and thus a very reliable rule, according to which verbs with a particular phonological structure display a particular (non-regular) conjugational pattern. By contrast, the assignment of the regular inflection is rather unpredictable, because it is phonologically (fairly) unspecific (unless supported by islands of reliability of its own; see Albright 2002, Albright \& Hayes 2003 and below). Albright (2002:66) calls rules that have a reliability value higher than average "islands of reliability". ${ }^{2}$ The regular conjugation is only used if the creation of a corresponding island of reliability is possible or as a default if no other specific rule can be created via minimal generalisation.

One conclusion from this is that the traditional view of conjugational classes that are grouped according to common phonological features of the verb stem, i.e. the well-known ablaut classes of Old High German, Old English and so forth, may be a more realistic conception of the German strong verbs than to simply treat them as irregular (see also Nübling 2000a:10). ${ }^{3}$ Note, however, that this does not concern the debate whether the weak verbs in Modern Standard German represent the regular or default conjugation, which is doubtless the case (see Bittner 1996: 64-70). Rather it supports the formation of conjugational classes on the basis of phonological root structure from a psycholinguistic point of view.

The theoretical concept of stems and paradigms is clearly in line with Albright's minimal generalisation hypothesis. Stems and paradigms are connected by implicative relationships, which are then exploited not only by the learner but, in fact, by any speaker of a language that possesses the

\footnotetext{
${ }^{2}$ For the definition and calculation of rule reliability cf. Albright (2002:687-689) and Albright \& Hayes (2003).

${ }^{3}$ This study follows Nübling (2000a:10, 267) in viewing regular and irregular as poles of a continuum. Note again that default only means 'do $\mathrm{x}$ if no other rule is available'; i.e. if a more reliable rule, which is based on a minimal generalisation involving e.g. the phonological root structure, can be found, the default does not apply. Likewise, irregular means 'not regular' but not 'defective, wrong' or anything like that.

On the basis of tests conducted with students of German Language and Linguistics in Berlin and Klagenfurt (Austria), Bittner (1996:68) claims that nonsense verbs never follow the strong pattern but always use regular (weak) forms. However, this test can hardly be called representative, as all subjects possessed substantial linguistic knowledge. Moreover, Bittner (1996:68) does not give any nonsense verbs matching the root-structure of strongly supported patterns, such as trinken trank - getrunken 'drink - drank - drunk'. According to Albright's (2002) minimal generalisation model, a pattern that is either not supported by many types or whose root structure is ambiguous does not present a very reliable rule, at least not one that can compete with the default model.
} 
relevant typological properties. From a more theoretical perspective, several studies have highlighted the significance of the implicational relations within a paradigm and the usefulness of stems as a way of deriving paradigmatic forms through generalisations (analogies) from other word forms of the same paradigm (see e.g. Wurzel 1989, Becker 1990, Albright 2002, Raffelsiefen 2002, Albright \& Hayes 2003, Blevins 2003 and Gafos 2003). One way of modelling the implicational relationships of a conjugational system is the principal-part analysis proposed by Finkel \& Stump (2006). In identifying those parts of a paradigm that permit the inference of the remaining word forms, the essence of a paradigm and a conjugational system can be captured and modelled, reflecting the generalisations that are used by learners as well as proficient speakers.

The diversity of representations of the Modern German strong verbs, sketched above, can be contrasted with the unity of analyses for older stages of German, i.e. Middle and Old High German, as well as Proto-Germanic, all of which agree on the categorisation into ablaut classes. Furthermore, most diachronic studies assert that after the Middle High German period the system of the strong verbs underwent drastic changes that make it difficult to uphold the traditional classification (see e.g. Kern \& Zutt 1977, Hempen 1988, Bittner 1996). Consequently, most studies abandon the traditional descriptive framework used for Old and Middle High German when moving on to Modern German. However, this conceptual change obscures the view on a good deal of the systemic development. Consequently, it is still not entirely clear what exactly constitutes the crucial systemic difference between the strong verbs in the older stages of German and those in Modern Standard German and what this means for an adequate synchronic (Modern German) and diachronic representation. ${ }^{4}$ Concerning the diachronic development, the strong verbs of Modern Standard German occupy an intermediate position in between a highly conservative pole, represented by Modern Icelandic, and a stage in which the notion of strong verbs is of little synchronic relevance, represented by Modern English (see e.g. Nübling 2000b).

In a bid to remedy this descriptive inconsistency, this paper points out the characteristics of the original system of the strong verbs in Proto-Germanic and compares this with the situation in Modern German, using the principal-part analysis proposed in Finkel \& Stump (2006). More precisely, the goal is to bring out the essence of the system of the strong verbs and the nature of the systemic change that has been observed in the literature within the unified framework of Finkel \& Stump's (2006) model, permitting a comparison from a shared perspective. The paper is organised as follows: Section 2 briefly introduces the concept of the principal-part analysis as advanced by Finkel \& Stump (2006) and proposes some additional correlations on systemic complexity. In section 3 the strong verbs of Proto-Germanic are analysed. Section 4 discusses changes that occurred in subsequent stages up to the Early Modern German period, before section 5 links up with an investigation of the strong verbs of Modern German. The main results are summarised in section 6 .

\section{The principal-parts model (Finkel \& Stump 2006)}

In general, the principal parts of a paradigm are those word forms that permit the prediction of the complete paradigm. For instance, the principal parts of Latin monère 'admonish, warn' are the first person singular present indicative active (moneo 'I admonish'), the first person singular perfect indicative active (mопиі 'I have admonished'), the perfect passive participle (monitum 'admonished') and the infinitive (monere), because the remaining paradigm can be deduced on the basis of these four forms. For instance, the imperfect indicative of monerre, monébam 'I admonished', is based on the infinitive, the pluperfect indicative (monueram 'I had admonished') on the perfect stem, and so forth. Thus, principal parts are of invaluable help to the language learner, because instead of memorising entire paradigms, only those forms have to be learnt that allow the deduction of the other paradigmatic word forms via pre-defined rules. However, this pedagogical application points to an underlying theoretical and linguistic significance of this methodological approach. Finkel \& Stump (2006:1) view principal parts as "a distillation of the implicative relations that exist among the members of a

\footnotetext{
${ }^{4}$ For instance, Hempen (1988:307-311) and Bittner (1996:172-174) both name the drastic increase of ablaut classes and the loss of productivity of the strong verbs as key developments. As will become clear below, although especially the fragmentation of the ablaut system has to be seen as an important development, from a systemic point of view other processes, such as the increasing functional significance of ablaut (see also Bittner 1996:173 and Wiese forthc.) and the destruction of the original system of class assignment, have to be viewed as predominant.
} 
lexeme's paradigm; they reveal an important domain of typological variation in morphology." Finkel \& Stump's (2006) model is also designed to provide a typological comparison of inflection systems. ${ }^{5}$

In traditional approaches that use principal parts (mostly called stem forms or stems), all paradigms of an inflection system possess the same principal parts, i.e. the same morphosyntactic categories act as stem forms in all paradigms; e.g. under the traditional concept all Latin verbs are characterised by the principal parts given above. ${ }^{6}$ The exponents of the principal parts then define an inflection class within the inflection system, e.g. the $1^{\text {st }}$ vs. the $2^{\text {nd }}$ conjugation of the Latin verbs. Systems in which principal parts are invariant across inflection classes are called static by Finkel \& Stump (2006). This is illustrated in Table 1 for a hypothetical conjugation system (capital letters denote morphosyntactic categories and the lower case letters refer to the exponents of a given category).

(1) Static principal parts (Finkel \& Stump 2006:2)

\begin{tabular}{|l|c|c|c|c|}
\hline & W & X & Y & Z \\
\hline I & a & e & i & m \\
\hline II & b & e & i & m \\
\hline III & c & f & j & n \\
\hline IV & c & g & j & n \\
\hline V & d & h & k & o \\
\hline VI & d & h & l & o \\
\hline
\end{tabular}

In (1), conjugation class I is defined by having $\mathbf{a}, \mathbf{b}$ and $\mathbf{i}$ as the exponents of the morphosyntactic categories $\mathbf{W}, \mathbf{X}$ and $\mathbf{Y}$, whereas class $\mathrm{V}$ is displays $\mathbf{d}, \mathbf{h}$, and $\mathbf{k}$ in the relevant columns. Note that category $\mathbf{Z}$ is not necessary for the identification of a conjugation class, because its exponents can be deduced from the exponents of categories $\mathbf{W}, \mathbf{X}$ and $\mathbf{Y}$ (cf. below on the requirement of minimality).

However, there are also more flexible ways of employing principal parts to conceptionalise a paradigm. In an adaptive system principal parts are ordered hierarchically, but they are not necessarily the same for each inflection class.

(2) Adaptive principal parts (Finkel \& Stump 2006:3)

\begin{tabular}{|l|c|c|c|c|}
\hline & W & X & Y & Z \\
\hline I & a & e & i & m \\
\hline II & b & e & i & m \\
\hline III & c & f & j & n \\
\hline IV & c & g & j & n \\
\hline V & d & h & k & o \\
\hline VI & d & h & l & o \\
\hline
\end{tabular}

The exact configuration of principal paradigmatic forms in relation to the first principal part, which is modelled as the top of a tree, identifies an inflection class. For instance, instead of the three principal parts that are traditionally assumed, the paradigms of some strong verbs of Modern German can be better conceptualised adaptively (see Tables 2 and 3 below for reference). This can be exemplified with dreschen 'thresh' and messen 'measure': Both verbs have the same exponent as the realisation of their first principal part (present stem), in this case the same stem vowel of the infinitive, but the fact that the preterit of dreschen is drosch automatically implies that the past participle is gedroschen, whereas the fact that the preterit of messen is maß means that its past participle is gemessen. Note, however, that in adaptive systems only the first principal part represents the same morphosyntactic property across all conjugation classes; this does not necessarily have to be valid for the remaining principal parts, as exemplified in (2) above. However, though Finkel \& Stump (2006) do not explicitly say this, the tree-like structure of an adaptive system means that the exponent of a higher node

\footnotetext{
${ }^{5}$ Though Finkel \& Stump (2006) illustrate their approach only with verbal paradigms, they (2006:1) explicitly assume its general validity for other lexical categories.

${ }^{6}$ See Finkel \& Stump (2006) for an alternative concept, using a dynamic approach. Likewise, didactic grammars of Latin make use of dynamic concepts for particular classes.
} 
determines the choice of the principal part for all classes sharing that same exponent. Assume, for instance, an additional class VII with the configuration $\mathbf{d}, \mathbf{x}, \mathbf{l}, \mathbf{0}$ as exponents of the morphosyntactic categories in (2). It is clear that this class could be best identified by the set $\{\mathbf{W}, \mathbf{X}\}$. However, the adaptive approach requires that all classes with $\mathbf{d}$ as the exponent of $\mathbf{W}$ have to a common second principal part. Therefore, a characterisation of classes $\mathrm{V}$ and VI by the set $\{\mathbf{W}, \mathbf{Y}\}$ and the identification of class VII by the set $\{\mathbf{W}, \mathbf{X}\}$ in the same adaptive system is impossible. This leaves a choice of either $\{\mathbf{W}, \mathbf{Y}\}$ for class V and $\{\mathbf{W}, \mathbf{Y}, \mathbf{X}\}$ for classes VI and VII, or $\{\mathbf{W}, \mathbf{X}\}$ for class VII and $\{\mathbf{W}, \mathbf{X}, \mathbf{Y}\}$ for classes V and VI (see 2' below, showing the alternative paths as $\mathbf{d}$ and $\mathbf{d}$ ').

(2') Tree model of the modified system in (2)

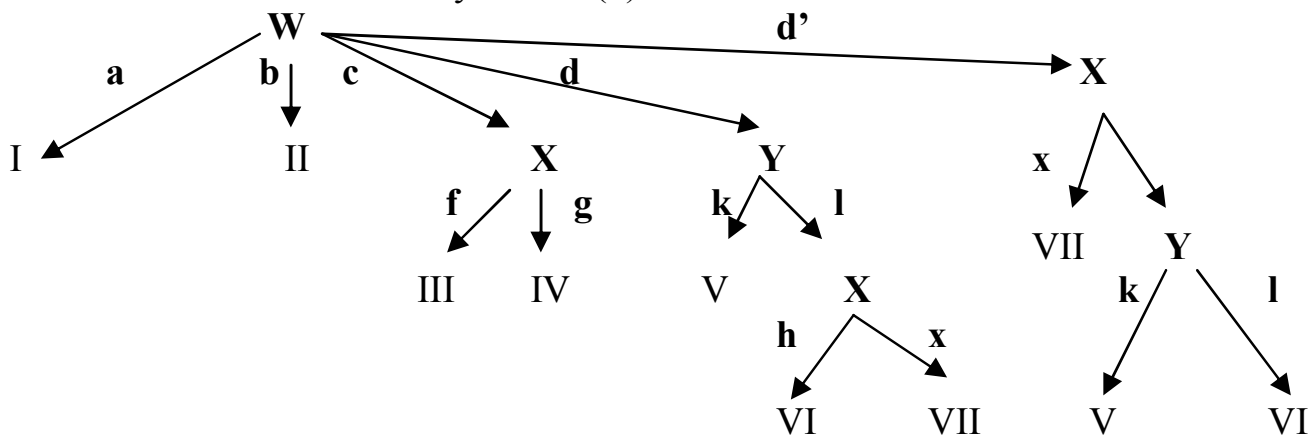

The computer program used to calculate the different principle-part systems automatically selects the path of principal parts that allows a minimal set of principal parts for the entire branch. ${ }^{7}$ This means that in the assumed scenario both pathways would in fact be treated as equal, since the total number of principal parts required is identical; there are always two classes that require three principal parts as opposed to one that is sufficiently defined by two. (2') illustrates the hierarchical structure of the modified adaptive system in (2), i.e. including the new class VII, with a tree structure adapted from Finkel \& Stump (2000: 3). This follows from the calculations by the computer program for Modern German (see section 5.3, Table 3) and also from the adaptive calculation for the Latin verb system in Finkel \& Stump (2006:27-28).

In a dynamic system a conjugational class is characterised by a completely free combination of the members of the paradigm as principal parts, which does not have to be the same for all classes in the system. The following diagram of our hypothetical system illustrates this perspective. Note that this describes an optimal dynamic system with other configurations also possible (see below).

(3) Dynamic principal parts

\begin{tabular}{|l|c|c|c|c|}
\hline & W & $\mathbf{X}$ & $\mathbf{Y}$ & $\mathbf{Z}$ \\
\hline I & $\mathbf{a}$ & $\mathbf{e}$ & $\mathbf{i}$ & $\mathbf{m}$ \\
\hline II & $\mathbf{b}$ & $\mathbf{e}$ & $\mathbf{i}$ & $\mathbf{m}$ \\
\hline III & $\mathbf{c}$ & $\mathbf{f}$ & $\mathbf{j}$ & $\mathbf{n}$ \\
\hline IV & $\mathbf{c}$ & $\mathbf{g}$ & $\mathbf{j}$ & $\mathbf{n}$ \\
\hline V & $\mathbf{d}$ & $\mathbf{h}$ & $\mathbf{k}$ & $\mathbf{0}$ \\
\hline VI & $\mathbf{d}$ & $\mathbf{h}$ & $\mathbf{l}$ & $\mathbf{0}$ \\
\hline
\end{tabular}

Comparing the different concepts of principal-parts systems proposed by Finkel \& Stump (2006), in a static system, $\mathbf{W}, \mathbf{X}$ and $\mathbf{Y}$ constitute static principal parts in all six classes; $\mathbf{Z}$ cannot be used to define the conjugation class, and it is not a principal part, because then the set would not be minimal (see below). An adaptive conception of our hypothetical conjugation system features $\mathrm{W}$ as a principal part for all six classes. But whereas in classes I and II this alone is enough to define the class, in classes III and IV the exponent of $\mathbf{X}$ is needed as an additional principal part. Classes V and VI, by contrast, are defined by $\mathbf{W}$ as well as $\mathbf{Y}$ (see 2). With a dynamic concept (see 3 above), the exponents of $\mathbf{W}, \mathbf{X}$ and $\mathbf{Y}$ on their own permit the inference of the conjugational class. Hence, class V, for example, is

\footnotetext{
${ }^{7}$ A computer program devised by Raphael Finkel and Greg Stump can be used to calculate the different options (http://www.cs.uky.edu/ raphael/linguistics/principalParts.html).
} 
identified by $\mathbf{k}$ as exponent of $\mathbf{Y}$. In general, one conjugational system can be described using alternative principal-part conceptions (see 1 to 3 above). Note that the three systems described by Finkel \& Stump (2006) can actually be seen as part of a continuum. A dynamic system is simply the least restricted way of defining conjugational classes, whereas under the two other approaches at least one common defining morphosyntactic category is set for the entire system. As a result, the dynamic view already includes possible adaptive and static conceptualisations; the relevant parameters (see also below) just have to be set accordingly.

Finkel \& Stump (2006) present additional criteria to categorise principal-part systems typologically, which then permits the comparison of different systems. The first is the number of principal parts needed to describe an inflection system. As mentioned above, the different concepts operate with different numbers of principal parts. According to Finkel \& Stump (2006:9), generally, "a static system for a given language involves the largest number of principal parts, and a dynamic system for the same language involves the smallest".

The second classificatory parameter proposed by Finkel and Stump (2006) is the consistency of its principal parts, i.e. whether principal parts are the same for all inflection classes (parallel system) or not (skewed system). This separates static systems (parallel by definition) from adaptive and dynamic ones (parallel or skewed). ${ }^{8}$ A third distinction is made between segregated and integrated systems. In the former case a non-principal part is always derived from a single principal part, whereas in the latter case non-principal parts have to be inferred from more than one principal part. As an example of an integrated system consider the traditional (static) version of the Latin verb system. Though the majority of forms can be deduced using one principal part, in some cases two principle parts are

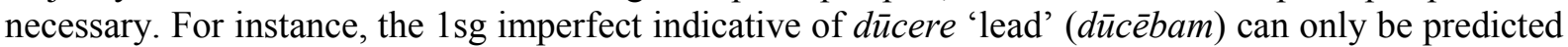
from the infinitive and the $1 \mathrm{sg}$ present indicative $d \bar{u} c \bar{o}$ together, as from the infinitive alone it would be unclear whether the $1 \mathrm{sg}$ imperfect indicative was dücébam or potentially *düciēbam (cf. capere 'take' : capiēbam : capiō) and the 1sg present indicative on its own in this case does not permit the inference of the imperfect indicative either (see also Finkel \& Stump 2006:23-28). By contrast, in the dynamic version each class is identifiable by only one principal part, which makes the system segregated.

The next criterion is whether the morphological shape of a principal part is shared by the nonprincipal parts that are deduced from it (morphologically coherent), or whether both have no morphological connection (morphologically incoherent), a case that would be exemplified by a suppletive paradigm. The last criterion proposed by Finkel \& Stump (2006: 20) determines whether "corresponding word forms in distinct paradigms [are] determined by the same dynamic parts" (isomorphic) or not (non-isomorphic). ${ }^{9}$ Thus, a system that identifies stem forms in a traditional (static) way is usually also isomorphic, such as e.g. the verb system of Sanskrit. Conversely, a skewed system, which really brings out the strength of the dynamic concept, cannot be isomorphic. As there may be several ways of modelling one and the same inflection system, there is the question of optimality. According to Finkel \& Stump (2006:2) a model is optimal if it is both adequate and minimal. The term adequate applies if the proposed principal parts are sufficient to correctly predict the entire paradigm and the term minimal if the proposed set of principal parts is the smallest possible.

However, another aspect in the typological comparison of two systems seems to be that of simplicity, an issue that is only addressed briefly by Finkel \& Stump (2006:18). The overview of all "logically possible dynamic parts systems" given by Finkel \& Stump (2006:22) may also be interpreted in terms of rising complexity, from which I have deduced the postulates of complexity in (4) below. This could also be understood in the sense that a complex system is more difficult to learn than a less complex one, which, of course, would have to be tested independently.

(4) Complexity correlations for principal part systems

a. A static system is less complex than an adaptive one; a dynamic system is the most complex.

\footnotetext{
${ }^{8}$ Finkel \& Stump (2006:11 fn. 4) point out that the combination of this criterion with the basic type of system can be described in terms of optimality. Thus, a dynamic system that is parallel is not optimal, because it lacks the specific flexibility that the definition of a dynamic system allows. As a result, the postulation of a dynamic inflection system is the most adequate for skewed systems, because it brings out the full strength of the dynamic approach.

${ }^{9}$ It is in principle possible to set up a dynamic system that is both parallel and non-isomorphic (though the reverse is not), but this is not optimal, as in some inflection classes principal parts would be redundant (cf. also fn. 8 above).
} 
b. The more principal parts a system has, the more complex it is.

c. Segregated systems are simpler than integrated ones.

d. Morphologically coherent systems are less complex than morphologically incoherent ones.

e. Isomorphic systems are simpler than non-isomorphic ones.

Reinterpreting Finkel \& Stump's (2006:22) preliminary typological survey, it can be seen that the verb system of Sanskrit (more than one principal part, parallel, segregated, coherent and isomorphic), for example, is considerably less complex than that of Latin (more than one principal part, skewed, integrated, coherent and non-isomorphic) and that the languages Fur and Comaltepec Chinantec are examples for the most complex verb systems conceivable under the proposed model (both more than one principal part, skewed, integrated, incoherent and non-isomorphic).$^{10}$ In the following sections this model is applied diachronically to the system of the strong verbs in order to bring out the systemic changes that it underwent in the development from Proto-Germanic to Modern German.

\section{The strong verbs of Proto-Germanic}

The identification of two basic types of verbs, traditionally labelled strong and weak, is one of the hallmarks of the Germanic languages. The two groups can first of all be differentiated morphologically: The strong verbs use ablaut to form their paradigmatic stems (cf. e.g. Mod.E sing sang - sung), whereas the weak verbs display a suffix, the so-called dental suffix, visible in -ed in Modern English (e.g. play-ed) and -t- in Modern German (e.g. spiel-t-e 'played'). From a synchronic point of view, the strong verbs are primary verbs, i.e. they are not derived from other verbal or nominal bases, whereas the weak verbs comprise the secondary, i.e. derived, verbs. This distinction is still visible in the older stages of the Germanic languages; the weak verbs systematically display derivational suffixes that are absent from the great majority of the strong verbs and that reveal the semantic relation to the derivational base, e.g. OHG offan-ōn 'open' from offan 'open' and fülèn 'rot' from $f \bar{u} l$ 'rotten'. ${ }^{11}$ This means that in Proto-Germanic both verbal subsystems can generally be differentiated on the basis of their present tense stem, and hence their infinitive form, used also as the citation form, i.e. the citation form of the mental lexicon (see also Hempen 1988:121 and Bittner 1996:115). The Germanic verb system is characterised by several innovations that set it apart from the verb system of the parent language and the other Indo-European languages. For the strong verbs several morphological key features have to be noted (in detail see Mailhammer 2007, in press).

First, in contrast to the verb system of Proto-Indo-European, ablaut in the Germanic strong verbs fulfils a morphological function, since it is used as a marker of grammatical categories on the verbal stem and not as a redundant morphological property that is merely a concomitant of a particular type of stem formation. Second, the paradigmatic alternation of ablaut grades is the basis for the categorisation of virtually all strong verbs (the well-known ablaut classes) except for a small group that uses reduplication as a distinctive feature to mark the preterit. Third, the present stem formation of the strong verbs was drastically streamlined and reshaped according to one predominant model: Out of 20 different Indo-European types only a handful survived, and well over 90 per cent of all strong verbs belong to only a single type (see also Ringe 2006:174ff). As a result of this process of functionalisation and systematisation of ablaut and the uniformisation of stem formation, ablaut acquired the key position in the system of the strong verbs, a development that is found in no other Indo-European language. As already mentioned above, the position of ablaut in the verb system of Proto-Indo-European differs considerably from that in the strong verbs of Proto-Germanic. In the parent language ablaut is generally redundant in the formation of verb stems and hence largely without morphological function. Consequently, proposing ablaut classes for Proto-Indo-European (in e.g. Kern

\footnotetext{
${ }^{10}$ An anonymous reviewer raised the question whether the number of verbal categories expressed influences the complexity of a system. As far as principal parts are concerned, however, the number of categories realised does not play a crucial role, because what matters is the way their morphological realisations can be deduced. From this point of view, a system that contains a high number of verbal categories that are based on only one principal part appears to be considerably simpler that a system that expresses a relatively low number of categories based on more principal parts, which then have to be memorised individually.

${ }^{11}$ The few so-called jan-presents among the strong verbs (e.g. ${ }^{+}$bed-ja- 'ask, bid') can generally be identified as being primary from a semantic point of view. At any rate, they account for less than 5\% of all strong verbs (see Seebold 1970).
} 
\& Zutt 1977, Voyles 1992 and Bittner 1996) does not make any sense at all, because the organisation of the Proto-Indo-European verb system does not revolve around ablaut. This is clearly a Germanicist perspective that transports the Germanic situation into the parent language without reflecting the linguistic reality (for a detailed discussion see Mailhammer 2007). In fact, the Indo-Europeanist literature does not describe the Proto-Indo-European verb system with the help of ablaut classes (see e.g. Meier-Brügger 2002 and Tichy 2004). Table 1 shows the conjugational classes of the strong verbs in Proto-Germanic (adapted from Mailhammer 2007). ${ }^{12}$

Table 1: The conjugational classes of the Proto-Germanic strong verbs

\begin{tabular}{|c|c|c|c|c|}
\hline $\begin{array}{l}\text { CLASS: root } \\
\text { structure } \\
\text { abstraction } \\
\text { distributi } \\
\text { sample } \\
\text { form }\end{array}$ & $\begin{array}{l}\text { PRESENT TENSE } \\
\boldsymbol{e} \text {-full grade: } \\
\text { (ind., subj., imp., } \\
\text { inf., part.) } \\
\text { INFINITIVE }\end{array}$ & $\begin{array}{l}\text { PRET. SINGULAR } \\
\boldsymbol{a} \text {-full grade } \\
1^{\mathrm{ST}} \text { PERSON SING. }\end{array}$ & $\begin{array}{l}\text { PRET. PLURAL } \\
\text { zero grade } \\
\text { (pl., subj.) } \\
1^{\mathrm{ST}} \text { PERSON PL. }\end{array}$ & $\begin{array}{c}\text { PAST PARTICIPLE } \\
\text { zero grade }\end{array}$ \\
\hline $\begin{array}{l}\text { C } \square i C- \\
+{ }_{s t} \square i g- \\
\text { 'ascend' }\end{array}$ & $\begin{array}{ll}e \mathbf{F} \quad \text { CeiC- } \\
\\
\quad{ }^{+} \text {steiga- }\end{array}$ & $\begin{array}{l}a \mathbf{F} \quad \text { CaiC- } \\
\\
{ }^{+} \text {staig- }\end{array}$ & $\begin{array}{l}\text { Z CO } i \mathrm{C}- \\
\quad{ }_{\text {stigum }}\end{array}$ & 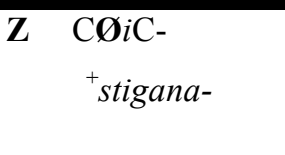 \\
\hline $\begin{array}{l}\text { II } \quad \text { C } u \text { C- } \\
{ }^{+} k \square u s- \\
\text { 'choose' }\end{array}$ & $\begin{array}{l}\text { eF } \quad \text { CeuC- } \\
\quad{ }^{+} \text {keusa- }\end{array}$ & $\begin{array}{r}a \mathbf{F} \quad \text { CauC- } \\
{ }^{+} k a u s-\end{array}$ & $\begin{array}{l}\text { С Øис- } \\
{ }^{+} \text {kuzum }\end{array}$ & $\begin{array}{l}\text { Z } \quad \text { Øи }- \\
{ }^{+} \text {kuzana- }\end{array}$ \\
\hline $\begin{array}{l}\text { III CDCC- } \\
+f \square n p- \\
\text { 'find' }\end{array}$ & $\begin{array}{c}\text { eF } \quad \text { eCC- } \\
\quad+f e n p a-\end{array}$ & $\begin{aligned} a \mathbf{F} \quad \text { CaCC- } \\
\\
{ }^{+} \text {fanp- }\end{aligned}$ & $\begin{array}{c}\mathbf{Z} \quad \mathrm{CuCC}-{ }^{13} \\
\quad \text { fundum }\end{array}$ & $\begin{array}{ll}\mathrm{Z} & \mathrm{CuCC}-{ }^{14} \\
& { }^{+} \text {fundana- }\end{array}$ \\
\hline $\begin{array}{ll}\text { IV } & \text { C } \square \mathrm{R}- \\
& { }^{+} n \square m- \\
& \text { 'take' }\end{array}$ & $\begin{array}{l}e \mathbf{F} \quad \text { CeR- } \\
\quad+{ }_{n e m a-}\end{array}$ & $\begin{array}{l}a \mathbf{F} \quad \text { CaR- } \\
\quad{ }^{+} \text {nam- }\end{array}$ & $\begin{array}{ll}\boldsymbol{e} \mathbf{L} & \mathrm{C} \overline{\boldsymbol{e}}_{1} \mathrm{R}- \\
& { }_{n}^{+} \overline{\boldsymbol{e}}_{1} m u m\end{array}$ & $\begin{array}{ll}\mathbf{Z} \quad & \mathrm{CuR}-{ }^{14} \\
& { }^{+} \text {numana- }\end{array}$ \\
\hline $\begin{array}{l}\text { V } \\
\text { C口C- } \\
+g \square b- \\
\text { 'give' }\end{array}$ & $\begin{array}{l}\boldsymbol{e} \mathbf{F} \quad \text { CeC- } \\
\quad+g e b a-\end{array}$ & $\begin{aligned} a \mathbf{F} \quad \text { CaC- } & \\
& +g a b-\end{aligned}$ & $\begin{array}{ll}\boldsymbol{e} \mathbf{L} \quad & \mathrm{C} \overline{\boldsymbol{e}}_{1} \mathrm{C}- \\
& { }^{+} g \overline{\boldsymbol{e}}_{1} b u m\end{array}$ & $\begin{array}{ll}e \mathbf{F} & \text { CeC- } \\
& + \text { gebana- }\end{array}$ \\
\hline
\end{tabular}

\footnotetext{
${ }^{12} \mathrm{C}=$ Consonant, $\mathrm{V}=$ Vowel, $\mathrm{R}=$ sonorant, $\mathrm{F}=$ full grade, $\mathrm{L}=$ lengthened grade, $\mathrm{Z}=$ zero grade. $\mathrm{I}$ use the raised cross $\left({ }^{{ }^{+}}\right.$) to mark a reconstructed form; the asterisk ('*') indicates an ungrammatical form. In quotations the authors' use is respected. This table omits the present preterits, as they have a weak preterit; at any rate, they are unambiguously identifiable from their first person singular present indicative, which does not show any personal ending.

${ }^{13}$ The zero grade in these forms manifests itself as PGmc. $u$ ( $\mathrm{PIE}^{+} \mathrm{R}_{\circ}>\mathrm{PGmc}^{+} u \mathrm{R}$ ). Most verbs in class III have a sonorant either directly preceding or following the nuclear vowel (see also van der Rhee 1973, Bammesberger 1986:57, Hempen 1988:96-100, Mailhammer 2007.).
} 


\begin{tabular}{|c|c|c|c|c|}
\hline $\begin{array}{cc}\text { VI } & \text { CDC- } \\
& { }^{+} f \square r- \\
& \text { 'go' } \\
& \end{array}$ & 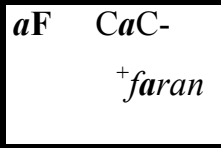 & $\begin{aligned} & \boldsymbol{o L} \quad \mathrm{C} \overline{\boldsymbol{o}} \mathrm{C}- \\
& \\
&{ }^{+} f \overline{\boldsymbol{\sigma}} r-\end{aligned}$ & $\begin{array}{l}\boldsymbol{o} \mathbf{L} \quad \mathrm{C} \overline{\boldsymbol{o}} \mathrm{C}- \\
\quad{ }^{+} \text {forum }\end{array}$ & 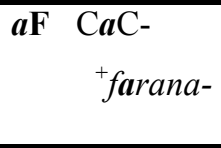 \\
\hline 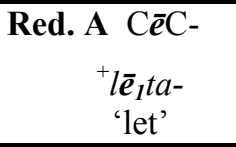 & 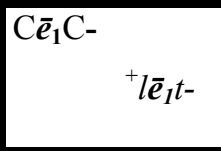 & 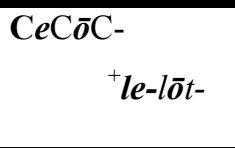 & $\begin{array}{l}\mathrm{CeC} \overline{\mathbf{o}} \mathrm{C}- \\
\quad{ }^{+} \text {le-lotum }\end{array}$ & $\begin{array}{l}\mathrm{C} \overline{\boldsymbol{e}}_{\mathbf{1}} \mathrm{C}- \\
\quad+{ }^{+} \bar{e}_{1} \text { tana }-\end{array}$ \\
\hline $\begin{array}{c}\text { Red. B CVC- }{ }^{14} \\
{ }^{+} \text {maita- } \\
\text { 'cut' }\end{array}$ & $\begin{array}{l}\text { CVC- } \\
\\
\\
+ \text { mait- }\end{array}$ & $\begin{array}{l}\mathrm{CeCVC}- \\
\quad+\text { me-mait- }\end{array}$ & $\begin{array}{l}\text { CeCVC- } \\
\quad+\text { me-maitum }\end{array}$ & $\begin{array}{l}\text { CVC- } \\
\quad{ }^{+} \text {maitana- }\end{array}$ \\
\hline
\end{tabular}

This table reads as follows: The first column lists the different conjugational classes, differentiated into ablauting verbs (classes I to VI) and the reduplicative verbs with ablaut (A) and without ablaut (B). The following four columns contain the traditional stem forms, representing the morphosyntactic categories in the top row. The functionalisation of ablaut in the ablauting verbs is clearly visible from the fact that the ablaut vowel is the only property that characterises a given stem and thus a grammatical category. From a systematic point of view, note how the different classes reflect different patterns of ablaut alternation. For example, the pattern $e-a$ - lengthened grade - zero grade is characteristic for class IV. As can be seen from Table 1, every class is specified by a particular root structure, which is represented as an abstraction in the leftmost column of Table 1 . This means that all strong verbs sharing particular features in their root structure, i.e. the root vowel and the root-final consonants/semivowels, have the same alternation of ablaut grades (see also van Coetsem 1990:33). The relevant root structure can be inferred directly from the present tense stem. For instance, ${ }^{+}$nema'take' with $e$ as a root vowel and a following single sonorant belongs to class IV and so do ${ }^{+}$bera'carry', ${ }^{+}$stela- 'steal' and so forth. The position of the ablauting vowel is like an empty slot that is filled according to the pre-defined pattern (indicated by the empty square in Table 1 ). ${ }^{15}$ its lexical significance is clearly limited (see also Kortlandt 1992:104). This kind of templatic ${ }^{16}$ use of ablaut is typologically reminiscent of the Semitic-style ablaut and not at all typical of an Indo-European language (see also Mel'čuk 1976:281, Kortlandt 1992, Scheer 1998 and Mailhammer in press). Compare e.g. Modern Arabic $k$-t- $b$ 'write' with vocalisations such as katab-a 'he wrote' or $u$-ktub 'write!', where the inserted vowels specify grammatical and semantic relations. ${ }^{17}$

Originally, there were only two ablaut patterns in Pre-Proto-Germanic, one for verbs with $e$ as their root vowel and one for verbs with $a$ (see van Coetsem 1990). But sound changes at the beginning of the Proto-Germanic period caused an early fragmentation of the $e$-system into five classes with four different ablaut patterns, a trend that continued in the post-Germanic stages (see sections 4 . and 5. below). The reduplicating verbs fit neatly into this system, as they are also unambiguously identifiable on the basis of their root structure. Thus, the fact that the citation form automatically indicates the class and therefore the specifications for the stem forms, which in turn permit the construction of the entire paradigm, makes this system extremely learner-friendly. As a result, the paradigm of any ProtoGermanic strong verb can be deduced from one form, the present tense stem, which is contained in the citation form, i.e. the infinitive.

\footnotetext{
${ }^{14}$ This symbolises the following root structures: CōC- $\left({ }^{+}\right.$blōta- 'sacrifice'), CaiC- ( ${ }^{+}$haita- 'to call, command'), CauC('auka- 'increase, augment'), CaRC- ('falla- 'fall'), all of which follow the same pattern. They form their preterit stem with reduplication but without ablaut; thus ${ }^{+}$beblōt- 'sarificed' (simplified onset of the reduplicative, cf. Vennemann 1997), "hegait- 'called' ( $g$ is due to the effect of Verner's Law, cf. Vennemann 1994, 1997), and so forth.

${ }^{15}$ The notation of the ablaut slot as an empty square was suggested to me by Theo Vennemann (Munich) in lecture courses and seminars.

${ }^{16}$ For the term see Rubba (2001).

${ }^{17}$ It is obvious that ablaut is used far more extensively in the Semitic languages than in Proto-Germanic. The point made here is that the systemic use of ablaut, i.e. as the insertion of pre-defined vowels into a mainly consonantal 'root-skeleton', is similar. This differs clearly from the Indo-European type, in which ablaut refers to a morphologically redundant change of the root vowel; the root vowel also carries lexical information, which it does not in the Semitic system. In that sense ablaut in Proto-Germanic resembles the Semitic type, and it thus occupies an intermediate position between the Semitic and the IndoEuropean type (for a detailed discussion see Mailhammer 2007).
} 
A principal-part analysis of the Proto-Germanic strong verbs reveals that there is actually only one principal part, regardless of whether a static, adaptive or dynamic concept is used. ${ }^{18}$ The citation form (= infinitive) automatically permits the inference of the whole paradigm, which is constructed either through the insertion of the pre-defined ablaut pattern into the root (classes I to VI), or through the use of reduplication (Red. B; note that, apart from a few exceptions, e.g. ${ }^{+} s \bar{e}_{l} p a-$ 'sleep', the verbs in Red. A display ablaut in addition to reduplication). The system thus is parallel, as it is always the infinitive form that serves as the principal part. In addition, it is segregated, because the non-principal parts are always deduced from only one principal part. Furthermore, it is morphologically coherent, since the stem as a template remains stable throughout the paradigm, and finally the system is isomorphic, because the word forms in the paradigm are always inferred from the same principal part in all conjugational classes. Thus, the strong verbs of Proto-Germanic form the simplest principal part system conceivable according to in Finkel \& Stump's (2006:22) typology (same specifications as Kwerba, a language spoken in Trans-New Guinea; Irian Jaya). For example, both Latin and Sanskrit possess verb systems that are far more complex (cf. Finkel \& Stump 2006:22).

\section{Old and Middle High German}

The system of the Germanic strong verbs experiences several system-relevant changes, which can be briefly summarised as follows. The most obvious ones are certainly the fragmentation of the system into subclasses due to regular sound change (see Hempen 1988, Bittner 1996 for more details and additional developments) and the transformation of reduplication into an ablaut-like vowel alternation, leading to the formation of class VII (see Vennemann 1994, 1997). For instance, class I splits up into two classes, reflecting the monophthongisation of WGmc. ${ }^{+} a i>\mathrm{OHG} \bar{e}$ before $r, w, h$ :

(4) Fragmentation of the ablaut system (class I)

a) OHG rītan : reit (WGmc. ' raid-) : ritum : giritan 'ride'

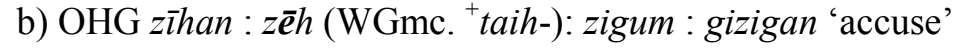

In addition to causing the fragmentation of the system, sound change is also responsible for the complete breakdown of the templatic use of ablaut. Instead of inserting a particular ablaut grade into the root, vowels alternate.
a. PGmc. ${ }^{+} b \boldsymbol{e u d a -}:{ }^{+} b \boldsymbol{a u d}-:{ }^{+} b \boldsymbol{u} d u m-:{ }^{+}$budana- 'bid' $e: a: \varnothing\left({ }^{+} b u d a-\right)^{19}$
b. OHG biotan : (biutu) $:$ b $\overline{\boldsymbol{\sigma}}$ : butum : gibotan 'bid, offer' ${ }^{20}$

Although both developments cannot be regarded as substantial changes, in the sense that they do not change the system's configuration according to the criteria proposed by Finkel \& Stump (2006), they, however, make the system less easy to use, because the speakers have to memorise more ablaut alternations than in Proto-Germanic. On the functional level, the increasing syncretism of personal endings, resulting mostly from vowel reductions noticeable from late Old High German onwards, means that more and more word forms in the paradigms of the strong verbs are differentiated only by ablaut, whereas before then the functional significance of ablaut was largely confined to the verb stem.

(6) MHG wir helf-en (1pl. pres. ind.) vs. wir hulf-en (1pl pret. ind.)

\footnotetext{
${ }^{18}$ The analysis was carried out on $2^{\text {nd }}$ August 2006 using the program mentioned in $\mathrm{fn} .7$. The input was an adapted version of Table 1, specified the root vowel and the root final sounds of each traditional stem form. The clear result was that the first stem form always permits the inference of the remaining forms, and therefore it constitutes the only principal part. The system is optimal (cf. Section 2. above) according to the criteria in Finkel \& Stump (2006), because it is both adequate (explains the entire paradigm) and minimal (no smaller set can be found).

${ }^{19}$ As in Table 1, the empty box signifies the slot of the ablauting vowel.

${ }^{20}$ The relevant sound changes can be found in the literature (e.g. Braune \& Reiffenstein 2004). They are listed here for convenience:

- $\quad$ PGmc. ${ }^{+} e u>$ OHG io (lowering before $a, e, o$ ).

PGmc. ${ }^{+} e u>$ OHG $i u$ (raising before $i, u$ ).

PGmc. ${ }^{+} a u>$ OHG $\bar{o}$ (monophthongisation before $h, r$, dentals).

PGmc. ${ }^{+} u>\mathrm{OHG} o$ (lowering before $a, e, o$ except before NC-clusters).
} 
PGmc. ${ }^{+} h e l p-a m e z^{21}$ (1pl. pres. ind.) vs. ${ }^{+} h \boldsymbol{u} l p-\boldsymbol{m} \boldsymbol{e}$ (1pl pret. ind.)

In addition, from the Middle High German period onwards, strong verbs can no longer be differentiated from weak verbs by the phonological shape of the infinitive suffix. For instance, MHG sing-en 'sing' (strong) and fûl-en 'rot' (weak) are ambiguous compared with their Old High German counterparts sing-an and $f \bar{u} l-\overline{\boldsymbol{e}} \boldsymbol{n}$, in which the ending clearly indicates the conjugational subsystem (see also Bittner 1996:141).

As a result of these processes, the Middle High German system of the strong verbs has lost a great deal of its original elegance and simplicity, and the functional importance of ablaut has actually increased. In addition, the Proto-Germanic dichotomy of primary vs. secondary verbs, which was once semantically and morphologically fully transparent, has been obscured. Nevertheless, from the viewpoint of the principal-part approach nothing has changed, because the inference of an entire paradigm on the basis of one paradigmatic form, the citation form, still works for the great majority of the strong verbs. This is in disagreement with Hempen (1988:308) and Bittner (1996:143), who view the ablaut system as inoperative by the end of the Middle High German period. However, their arguments are problematic. The fact that the strong verbs are no longer productive on a large scale does not permit any inferences on the inner workings of the system. Similarly, the fact that the strong verbs are no longer formally distinguishable from the weak verbs does not imply an inoperative ablaut system. In fact, according to Albright's (2002) islands-of-reliability-hypothesis (cf. 1. above), speakers would still have a rather good chance of identifying a strong verb via its phonological root structure, because the classes are relatively coherent, and not many weak verbs have a matching root structure, which could have caused confusion. Hence, in Albright's terms, the formation rule for a strong verb, based on the phonological root structure, is highly reliable, which makes the identification of a strong verb highly probable. Hempen (1998:308f) tacitly adopts this point of view when she says that for productive formations of strong verbs "erfolgt die Zuordnung zu einer Flexionsklasse $\mathrm{Vb}$. für $\mathrm{Vb}$., wobei $\mathrm{Vb}$. mit Inf.-Strukturen, die lautlich umfangreicheren Ablautreihen entsprechen, eben st. flektieren." ['the association with an inflection class is different for every verb, with verbs inflecting according to the strong pattern if they possess infinitive forms corresponding phonologically to verbs from the bigger ablaut classes', my translation] This would seem implausible if the ablaut system had been inoperative by that time. From this discussion it follows that a separate calculation is not necessary for Old and Middle High German, because the system has not changed essentially from Proto-Germanic times despite the phonological and morphological developments described above: There is still one principal part from which the entire paradigm can be predicted, and this is the present stem form, although clearly more different ablaut patterns have to be memorised than in ProtoGermanic. As will become clear in the next section, this changes in Early Modern German, as a result of which the vast majority of the paradigms of the strong verbs in Modern German can no longer be inferred from one principal part. I will argue that this the crucial difference between the system of the strong verbs up to Middle High German and the strong verbs from Early Modern German onwards.

\section{The development of the strong verbs towards Modern Standard German}

\subsection{Developments in Early Modern German}

In the Early Modern German period the system of strong verbs is affected by several developments that eventually cause the breakdown of the original system of ablaut classes. Due to sound change and analogical formations that are not based on the infinitive form (= the principal part) in the wake of the standardisation of Modern German, the ablaut system experiences a new wave of fragmentation, spawning a total of over forty different ablaut patterns in Modern Standard German (see e.g. Reichmann \& Ebert 1993).

(7) Examples of sound change and analogy in Early Modern German

\footnotetext{
${ }^{21}$ As argued by Mailhammer (2007), the inherited thematic vowel (in this case $a$ ) has fused with the personal ending, since it has lost its morphological function in Proto-Germanic.
} 
a. PHONEMIC MERGER: MHG rîten 'ride' (class Ia) : heizen 'call, be called'(class VII) > Mod.G reiten, heißen ${ }^{22}$

$\rightarrow$ different ablaut patterns that can no longer be deduced from the phonological root structure

b. ANALOGY: EMod.G

sieden - sott - gesotten /o/ ('seethe')

bieten - bot - geboten /o:/ ('bid')

MHG sieden - (siude) - sôt - suten-gesoten /o/

bieten - (biute) - bôt - buten - geboten /o/ (both class IIb)

EMod.G schmelzen - schmolz-geschmolzen (cf. sieden, gießen)

MHG smelzen - (smilze) - smalz-smulzen - gesmolzen (class IIIb)

$\rightarrow$ basis for class allocation becomes opaque and arbitrary, as it can be based on any part of the paradigm and not only the present $\mathrm{stem}^{23}$

Another far-reaching change is the reduction of the number of simplex strong verbs by more than half (169 vs. 338 in Middle High German, according to Hempen 1988), either because verbs adopt the weak pattern, e.g. Mod.G pflegen 'care', or because they become extinct, e.g. MHG jehen 'speak'. ${ }^{24}$ Consequently, a large number of poorly supported patterns (with five or fewer members) emerge. This further undermines the stability of the strong-verb system, which makes individual strong verbs even more susceptible to taking over the weak pattern, as this is increasingly perceived as regular (cf. Hempen 1988:276, Bittner 1996:167). The main result of these processes is that the predictability of the paradigmatic stems on the basis of the present stem is lost, because two verbs with the same root structure may still follow different ablaut patterns (see also Newfield 1981:128, Bittner 1996:143). Consequently, all relevant stem forms are necessary to deduce a strong verb's paradigm rather than only the root of the citation form. As will become clear from the principal part analysis in the next section, this is the main difference between the strong verbs in Modern German and the strong verbs in the older stages of German.

In contrast to the above-mentioned weakening of the coherence of the ablaut system, the functional significance of ablaut is further strengthened. In particular, this is due to the levelling of the number distinction in the preterit of classes I to V (cf. also Table 1).

Levelling of number distinction in classes I to $\mathrm{V}$ and the expression of tense

MHG ich half 'I helped' vs. wir hulfen 'we helped': preterit marked by $\boldsymbol{a}$ and $\boldsymbol{u}$

Mod.G ich half'I helped' vs. wir halfen 'we helped': preterit marked by $\boldsymbol{a}$

$\rightarrow$ present: wir helfen 'we help' vs. preterit wir halfen ('we helped'), ich half 'I help'

$\rightarrow$ present marked by $\boldsymbol{e}$ and preterit marked by $\boldsymbol{a}$

As a result, a single ablaut grade now marks the complete category of tense (present : preterit) as opposed to tense with a further subdivision for number (present : preterit sg : preterit $\mathrm{pl}$ ). ${ }^{25}$ This simplifies the system and increases the distinctive power of ablaut even more (see also Bittner 1996: $157,173)$. Note, however, that verbs belonging to the traditional class VI have never had an ablaut difference between preterit singular and plural (for the development of class VI see Mailhammer 2007: 89-103). Likewise, in the transformation of the reduplicating verbs into class VII such a distinction did not develop. Therefore, the preterit tense in classes VI and VII (the former reduplicating verbs) is characterised by a uniform vowel grade from the beginning.

\subsection{The strong verbs in Modern Standard German}

\footnotetext{
${ }^{22}$ So-called Early Modern German Diphthongisation followed by a lowering of the nucleus, changing MHG $\hat{\imath} / \mathrm{i}$ :/ into Modern Standard German ei /ai/ .

${ }^{23}$ This is in fact a noteworthy difference to class changes in older stages of the Germanic languages.

${ }^{24}$ To some degree new strong verbs are formed in Middle High German and Early Modern German (see e.g. Hempen 194199), either through the integration of loanwords (e.g. pfeifen 'whistle' probably from L pipāre), or because weak verbs adopt the strong pattern (e.g. laden 'invite', preisen 'praise'). As noted in section 4 above, this development is obviously motivated by phonological analogy to well-supported classes of strong verbs and can be directly explained by the minimal generalisation hypothesis in Albright (2002).

${ }^{25}$ As argued in 5.2 below, the change in the present stem vowel from $e$ to $i$ in $e r$ hilft 'he helps' is part of the lexical entry, and hence does not have to be viewed as a separate stem.
} 
The developments described in 5.1 above resulted in a system with over forty different patterns of ablaut alternations, only about ten of which are well supported (more than ten members), with the rest ranging between one and ten members (see e.g. Hempen 1988:23-25) ${ }^{26}$ The tendency to give up the strong pattern can certainly be noticed, e.g. backen 'bake', mahlen 'grind', etc., but 'regularisations' of infrequent and irregular alternations modelled on a better-supported strong pattern rather than on the regular model can also be observed. Hence, *gehissen (a form produced in a test with German schoolchildren, cf. Kieferle \& Lindner 2003) instead of geheißen after reißen - gerissen by proportional analogy and not necessarily *geheißt by default, which again supports the islands-ofreliability-hypothesis advanced by Albright (2002), mentioned in section $1 .^{27}$ In most cases the phonological root structure of a strong verb is no longer characteristic of an ablaut pattern. Even approaches that attempt such generalisations, such as Helbig \& Buscha (2005), almost always have to note exceptions to their proposed rules or frequently propose rules of doubtful use. For instance, according to Helbig \& Buscha (2005:34), verbs with long and short $a$ plus $l, s$ or $t$ are grouped in a class 7a. However, schlafen 'sleep', empfangen 'receive', fangen 'catch' and hängen 'hang' are also put in this group despite the divergent root structure and although an additional note specifying that the preterit displays a short $i$ instead of a long one like in regular schlief 'slept', riet 'guessed' is necessary for the last three verbs. This shows that the root-final consonants have lost their significance for the classification of the Modern German strong verbs, which is the reason for their exclusion in the principal-parts analysis. ${ }^{28}$ Nevertheless, as mentioned above, analogical formations often take into account the post-nuclear sounds, even though they do not play any role in the abstraction of a conjugational class (recall the analogical formation of *gehissen mentioned above), an issue that will be taken up in 5.4 below. Conjugational classes usually share one ablaut pattern, i.e. the alternation of ablaut grades in one paradigm, which is the basis of the principal parts analysis in this paper.

As mentioned above, several systems are used in the literature to classify the strong verbs of Modern Standard German. Based on clear indications of the psycholinguistic significance of stems and paradigms, the principal parts analysis promises to be an excellent way of finding out what kinds of systems are possible and whether this represents a significant advantage over previous accounts. As will become clear further below, the traditional representation using stem forms and classes based on ablaut patterns is in fact a static principal part interpretation. Nonetheless, the remaining typological criteria put forward by Finkel \& Stump (2006) are important for the comparison of Modern German with Proto-Germanic and will also allow a more detailed picture of the system.

In order to apply the principal parts analysis, inflection classes have to be established. The diversity of classifications of the Modern German strong verbs in existing accounts shows that this is not trivial (cf. also Bittner 1996: 43-48). In line with Bittner (1996:48), a fairly traditional concept of inflection class - or conjugation class, as this paper deals only with verbs - is employed here. Accordingly, an inflection class contains words sharing the same morphological formation rules for their paradigms. There are several reasons for this choice. First, the construction of psycholinguistic correlates of paradigms is a necessary operation for the speaker. Second, speakers form generalisations about the construction of paradigms (see Albright 2002). Third, more abstract classifications, such as by Kern \& Zutt (1977), Hempen (1988) and Duden (2005), have a very limited field of application, because they do not necessarily predict the paradigmatic word forms. If, for instance, a class is formed on the basis that the present stem is different from the preterit stem, which in turn is the same as the

\footnotetext{
${ }^{26}$ In the literature a diverging number of ablaut patterns can be found (see e.g. Duden 1998:127). This mainly reflects different definitions of strong verbs and different views of the stem forms of a paradigm. This paper follows the quantification in Hempen (1988:23-25), because it is synchronically and diachronically the most consistent and convincing account. However, this does not include the sub-categorisations advanced there, reflecting vowel alternations going back to raising processes (change of stem vowel in the present tense and the preterit subjunctive), an issue that will be taken up further below in this section.

${ }^{27}$ Theo Vennemann (Munich, p.c.) reminds me that the regularisation of former strong verbs like mahlen and backen may also have been motivated by concrete regular models, such as zahlen 'pay' and hacken 'hack', which could be directly motivated by the minimal generalisation hypothesis (see also Albright \& Hayes 2003).

${ }^{28}$ To be fair, in singular cases islands of reliability that are particular reliable may thus escape the principal-parts analysis presented in this paper, a point also raised by Adam Albright (p.c.). But that does not influence the overall interpretation advanced here. Note further that a model for a generalisation may not always be found in the sense of an analogical proportion, as an anonymous reviewer points out. Rather, in some cases new forms are created in a way Albright \& Hayes (2003:153) call "product-oriented generalization", which means that vowel-change patterns are created ex nihilo as e.g. a past tense is formed after a frequent or particularly typical model.
} 
past participle stem (e.g. Class A in Hempen 1988), then this does not permit any prediction of the preterit stem, which, however, is crucial for the construction of the paradigm.

As all strong verbs in Modern Standard German show the same personal endings, with allomorphy being conditioned phonologically (for the rules see e.g. Duden 2005:462-463), they can be excluded as relevant factors in the establishment of conjugational classes. Thus, conjugational classes are defined on the basis of stem formation, which means that, firstly, a paradigm is described by its different stems, and secondly, that all verbs sharing the same formation rules for the construction of their paradigmatic stems are placed in the same class. In line with many classificatory systems of the strong verbs in Modern Standard German (e.g. Bittner 1996, Duden 2005, Helbig \& Buscha 2005), this kind of stem allomorphy is included as a separate rule in the lexicon and does not necessitate the establishment of a new conjugational class for reasons of simplicity and also because the number of these cases is relatively small. This holds for the few verbs that still show the effect of Verner's Law (G Grammatischer Wechsel 'grammatical alternation'), such as leiden 'suffer' vs. gelitten 'suffered' and cases like gehen - ging - gegangen 'go' and stehen - stand - gestanden 'stand'. Some classifications (e.g. Hempen 1988) also include the stem of the preterit subjunctive with umlaut (e.g. nähme, böge, etc.) and the change of the stem vowel in the second and third person of the present singular indicative (ich nehme vs. du nimmst, ich fahre vs. du fährst, etc.) as stem forms. However, this seems unnecessary considering that only certain vowels regularly show umlaut in the preterit subjunctive, namely back vowels - a generalisation that is also true for the change of the stem vowel in the present tense. In addition, verbs with $e$ as their stem vowel show an alternation between $i$ and $e$ in the present singular indicative. There are a few exceptions to both rules, e.g. sterben - stürbe, ich schaffe - du schaffst, but most accounts include their exceptionality and the regularity of umlaut/vowel change in the lexicon and do not set up a new conjugational class (cf. e.g. Bittner 1996:74-83, Helbig \& Buscha 2005:31, 168-171 and Wiese forthc.). Hence, the above-mentioned alterations in stem vocalism and consonantism are viewed as lexicalised for the purpose of this study. This means that conjugational classes, which are then conceptualised by principal parts, will only be based on forms displaying systematic and morphologically conditioned alternations of the stem vowel. As a result, the paradigm of a Modern German strong verb can be constructed using the stem of the present tense, from which all present stem forms can be deduced, that of the preterit, which permits the construction of the finite preterit forms, and the past participle. Note again that the citation form alone, i.e. the infinitive (= present stem) does not allow the unambiguous inference of the remaining stems. Nonetheless, a principal part analysis is required to find out whether these three stem forms are the only possible way of capturing the system of the strong verbs in Modern German, as there are cases in which fewer than three stems are enough to deduce the full paradigm.

\subsection{Three principal parts analyses of the strong verbs in Modern German}

The conjugational classes of the strong verbs in Modern Standard German are listed in Table 2, following Hempen (1988:23-25). Table 2 does not include the preterit-present verbs or any of the socalled gemischte ('mixed') verbs, as neither of them possesses strong forms throughout the entire paradigm.

Table 2: The strong verbs of Modern German

\begin{tabular}{|l|c|c|c|l|}
\hline Class & Present stem & Preterit stem & Past participle & Sample (total \#) \\
\hline 1 & $/ \mathrm{u} /$ & $/ \mathrm{d} /$ & $/ \mathrm{a} /$ & tun 'do' (1) \\
\hline 2 & /e/ & /a/ & $/ \mathrm{a} /$ & stehen 'stand' (1) \\
\hline 3 & /aI/ & /i/ & $/ \mathrm{i} /$ & bleiben 'stay' (17) \\
\hline 4 & /aI/ & /I/ & /I/ & reiten 'ride' (21) \\
\hline 5 & /e/ & /o/ & /o/ & heben 'lift' (5) \\
\hline
\end{tabular}

\footnotetext{
${ }^{29}$ Cf. Hempen (1998: 23-25); there are marginal differences to the quantifications in Bittner (1996), Duden (1998) and Helbig \& Buscha (2005), which are disregarded here. The vowel system follows the model proposed by Vennemann (1991) (see also Becker 1998, Restle 2003). The so-called vowel opposition (for the term see Becker 1998) is represented in terms of vowel quality; vowel quantity is only noted when necessary, i.e. /ع:/ vs. /ع/.
} 


\begin{tabular}{|c|c|c|c|c|}
\hline 6 & $/ \varepsilon: /$ & $/ \mathrm{o} /$ & $/ 0 /$ & gären 'ferment' (2) \\
\hline 7 & $/ \mathrm{i} /$ & $10 /$ & $10 /$ & fliegen 'fly' (11) \\
\hline 8 & $\mid \varnothing /$ & $1 \mathrm{o} /$ & $1 \mathrm{o} /$ & schwören 'swear' (1) \\
\hline 9 & $/ \mathrm{y} /$ & $/ \mathrm{o} /$ & $/ \mathrm{o} /$ & lügen 'lie' (2) \\
\hline 10 & /av/ & $10 /$ & $/ 0 /$ & saugen 'suck' (2) \\
\hline 11 & $/ \mathrm{a} /$ & $/ 2 /$ & $10 /$ & (er)schallen 'sound' (1) \\
\hline 12 & $/ \varepsilon /$ & $/ 2 /$ & $/ \mathrm{o} /$ & melken 'milk' (7) \\
\hline 13 & $/ \mathrm{i} /$ & $/ 0 /$ & $/ 0 /$ & schießen 'shoot' (11) \\
\hline 14 & $/ \mathrm{I} /$ & $10 /$ & $/ 0 /$ & klimmen 'climb' (2) \\
\hline 15 & $/ œ /$ & $/ \mathrm{O} /$ & $/ \mathrm{J} /$ & erlöschen 'extinguish' (1) \\
\hline 16 & /av/ & $/ 0 /$ & $/ 0 /$ & saufen 'drink, booze' (1) \\
\hline 17 & $/ \mathrm{I} /$ & $/ \mathrm{u} /$ & $/ \mathrm{v} /$ & schinden 'maltreat' (1) \\
\hline 18 & $/ \mathrm{e} /$ & $/ \mathrm{I} /$ & $/ \mathrm{a} /$ & gehen 'go' (1) \\
\hline 19 & $\mid \varepsilon /$ & $/ \mathrm{I} /$ & $/ \mathrm{a} /$ & hängen 'hang' (1) \\
\hline 20 & $/ \mathrm{i} /$ & $/ \mathrm{a} /$ & $/ \mathrm{e} /$ & liegen 'lie’ (1) \\
\hline 21 & $/ \mathrm{I} /$ & $/ \mathrm{a} /$ & $/ \mathrm{e} /$ & bitten 'ask' (1) \\
\hline 22 & $/ \mathrm{I} /$ & $/ \mathrm{a} /$ & $\mid \varepsilon /$ & sitzen 'sit' (1) \\
\hline 23 & $/ \varepsilon: /$ & $/ \mathrm{a} /$ & $/ 0 /$ & gebären 'give birth' (1) \\
\hline 24 & /e/ & $/ \mathrm{a} /$ & $/ 0 /$ & stehlen 'steal' (3) \\
\hline 25 & $/ \mathrm{e} /$ & $/ \mathrm{a} /$ & $/ 0 /$ & nehmen 'take' (1) \\
\hline 26 & $\mid \varepsilon /$ & $/ \mathrm{a} /$ & $/ 2 /$ & brechen 'break' (5) \\
\hline 27 & $/ \varepsilon /$ & $/ \mathrm{a} /$ & $/ 0 /$ & sterben 'die' (9) \\
\hline 28 & $/ \mathrm{I} /$ & $/ \mathrm{a} /$ & $/ 0 /$ & schwimmen 'swim' (6) \\
\hline 29 & $/ \varepsilon /$ & $/ \mathrm{u} /$ & $/ 0 /$ & werden 'become' (1) \\
\hline 30 & $/ \mathrm{I} /$ & $/ \mathrm{a} /$ & $/ \mathrm{u} /$ & finden 'find' (18) \\
\hline 31 & $/ \mathrm{a} /$ & $/ \mathrm{i} /$ & $/ \mathrm{a} /$ & blasen 'blow' (4) \\
\hline 32 & $/ \mathrm{a} /$ & $/ \mathrm{u} /$ & $/ \mathrm{a} /$ & fahren 'drive' (5) \\
\hline 33 & $/ \mathrm{a} /$ & $/ \mathrm{i} /$ & $/ \mathrm{a} /$ & fallen 'fall' (3) \\
\hline 34 & $/ \mathrm{a} /$ & $/ \mathrm{I} /$ & $/ \mathrm{a} /$ & fangen 'catch' (1) \\
\hline 35 & $/ \mathrm{a} /$ & $/ \mathrm{u} /$ & $/ \mathrm{a} /$ & wachsen 'grow' (4) \\
\hline 36 & $/ \mathrm{e} /$ & $/ \mathrm{a} /$ & $/ \mathrm{e} /$ & lesen 'read' (6) \\
\hline 37 & $\mid \varepsilon /$ & $/ \mathrm{a} /$ & $\mid \varepsilon /$ & essen 'eat' (4) \\
\hline 38 & $/ 0 /$ & $/ \mathrm{i} /$ & $/ \mathrm{o} /$ & stoßen 'thrust' (1) \\
\hline 39 & $/ \mathrm{d} /$ & $/ \mathrm{a} /$ & $/ 2 /$ & kommen 'come' (1) \\
\hline 40 & $/ \mathrm{u} /$ & $/ \mathrm{i} /$ & $/ \mathrm{u} /$ & rufen 'call, shout' (1) \\
\hline 41 & /aI/ & $/ \mathrm{i} /$ & $/ \mathrm{ai} /$ & heißen 'be called' (1) \\
\hline 42 & $/ \mathrm{av} /$ & $/ \mathrm{i} /$ & $/ \mathrm{au} /$ & laufen 'run' (2) \\
\hline
\end{tabular}

A preliminary issue to be addressed is the large number of conjugational classes of the strong verbs in Modern German, which is the result of the process of fragmentation described above. As Table 2 indicates, of the 42 classes in Modern German, 20 possess only one member, which makes the label class questionable. Hence, one could argue that there are in fact not 42 classes of strong verbs in Modern Standard German but only 22, with the 20 remaining classes/verbs being listed as exceptions or irregular verbs, just like denken 'think', bringen 'bring' and the group of the mixed verbs. In fact, research on English suggests that single-member classes do in fact differ qualitatively from better supported classes in the sense that they only very rarely form the basis for specific rules derived via minimal generalisations (Albright \& Hayes 2003:147-149), which supports their exclusion from the present analysis. However, in spite of this, single-member classes are included here for the following reasons. First, though there is suggestive indication of their irregular status and their non-availability as a basis for generalisations, the data does not rule out that single-member classes may function as a model pattern. The fact that this has simply not been recorded cannot be taken as conclusive proof. Second, in terms of the principle-part analysis carried out in this study, the exclusion of single- 
member classes does not alter the situation significantly. ${ }^{30}$ Third, from an inflectional point of view, those verbs in single-member classes in Table 3 still belong to the group of strong verbs, which is an additional argument for their inclusion in the present analysis. ${ }^{31}$

With the conjugational classes established, the next step of the analysis is the calculation of a static principal-parts system, which is really simple because, by definition, the static principal parts have to be the same for every class. Given that there are classes whose paradigm can only be deduced from all three stem forms, there must be three static principal parts and indeed this is the correct outcome as calculated by the computer program: ${ }^{32}$ "There are 42 conjugations, each with 3 MPSs [morphosyntactic property sets], a total of 16 exponences. Best sets of static principal parts: 1,2,3.”

The application of the remaining criteria set up by Finkel \& Stump (2006) shows that this static system is parallel (by definition, as the principal parts have to be invariant from one class to the other in a static system), segregated (each principal part is used to deduce a certain part of the paradigm, there are no overlaps), morphologically coherent (the consonantal part of the stem remains intact), and isomorphic (the same principal parts determine the same form in distinct classes). However, it is clear that having to memorise three principal parts for 42 classes is not necessarily learner-friendly, which is the reason for the application of more flexible systems. Table 3 displays the statistics for the adaptive system. It lists the principal parts that are needed to deduce the exponents of a given morphosyntactic category in a conjugational class in the order of the selection path (see section 2 above).

Table 3: Statistics for the adaptive system

\begin{tabular}{|c|c|c|c|c|c|}
\hline Class & Present stem (a) & Preterit stem (b) & Past participle (c) & Average & \# PP \\
\hline 1 & $\mathrm{a}$ & $\mathrm{a}, \mathrm{b}$ & $\mathrm{a}, \mathrm{b}$ & 1.67 & 2 \\
\hline 2 & $\mathrm{a}$ & $\mathrm{a}, \mathrm{c}, \mathrm{b}$ & $\mathrm{a}, \mathrm{c}$ & 2.00 & 3 \\
\hline 3 & $\mathrm{a}$ & $a, c$ & $\mathrm{a}, \mathrm{c}$ & 1.67 & 2 \\
\hline 4 & $\mathrm{a}$ & $\mathrm{a}, \mathrm{c}$ & $\mathrm{a}, \mathrm{c}$ & 1.67 & 2 \\
\hline 5 & $\mathrm{a}$ & $a, c, b$ & $\mathrm{a}, \mathrm{c}$ & 2.00 & 3 \\
\hline 6 & $\mathrm{a}$ & $a, b$ & $\mathrm{a}$ & 1.33 & 2 \\
\hline 7 & $\mathrm{a}$ & $a, b$ & $a, b$ & 1.67 & 2 \\
\hline 8 & $\mathrm{a}$ & $\mathrm{a}$ & $\mathrm{a}$ & 1.00 & 1 \\
\hline 9 & $\mathrm{a}$ & $\mathrm{a}$ & $\mathrm{a}$ & 1.00 & 2 \\
\hline 10 & $\mathrm{a}$ & $a, b$ & $a, b$ & 1.67 & 2 \\
\hline 11 & $\mathrm{a}$ & $a, b$ & $a, b$ & 1.67 & 2 \\
\hline 12 & $\mathrm{a}$ & $a, b$ & $a, b$ & 1.67 & 2 \\
\hline 13 & $\mathrm{a}$ & $a, b$ & $a, b$ & 1.67 & 2 \\
\hline 14 & $\mathrm{a}$ & $\mathrm{ab}$ & $a, b$ & 1.67 & 2 \\
\hline 15 & $\mathrm{a}$ & $\mathrm{a}$ & $\mathrm{a}$ & 1.00 & 1 \\
\hline 16 & $\mathrm{a}$ & $a b$ & $a, b$ & 1.67 & 2 \\
\hline 17 & $a$ & $a, b$ & $a, b$ & 1.67 & 2 \\
\hline 18 & $\mathrm{a}$ & $\mathrm{a}, \mathrm{c}, \mathrm{b}$ & $\mathrm{a}, \mathrm{c}$ & 2.00 & 3 \\
\hline 19 & $a$ & $\mathrm{a}, \mathrm{b}$ & $a, b$ & 1.67 & 2 \\
\hline 20 & $\mathrm{a}$ & $a, b$ & $a, b$ & 1.67 & 2 \\
\hline 21 & $\mathrm{a}$ & $a, b$ & $a, b, c$ & 2.00 & 3 \\
\hline 22 & $\mathrm{a}$ & $a, b$ & $a, b, c$ & 2.00 & 3 \\
\hline 23 & $\mathrm{a}$ & $a, b$ & $\mathrm{a}$ & 1.33 & 2 \\
\hline
\end{tabular}

\footnotetext{
${ }^{30}$ The number of static principal parts remains constant. In adaptive and dynamic systems there is a slight decrease $(1.45 / 1.9$ compared to $1.63 / 2.14$ in Table 3, and 1.55 compared to 1.78 in Table 4), though both systems still require a maximum of two principal parts. The only noteworthy change is that a dynamic system without single-member classes requires two principal parts at the most as opposed to the system in Table 4, which operates with a maximum of three.

${ }^{31}$ An anonymous reviewer raised the point of frequency, i.e. whether small classes should have the same weight as wellsupported ones and was also wondering about the significance of token frequency. Probably type frequency does indeed play a role in the case of competing class assignment, however, for the purpose of a principal-part analysis, which is designed to find out how many parts are necessary to deduce the paradigms of the verbs belonging to different conjugation classes in a given system, this is irrelevant. What matters is the number of available classes irrespective of their size (with the possible exception of single-member classes, whose role is discussed above). Though token frequency intuitively appears to be influential, recent research suggests that "patterns are extended on the basis of type frequency" rather than on the basis of token frequency (Albright \& Hayes 2003:133). For the token frequency of German verbs see e.g. Ruoff (1981:440-446).

${ }^{32}$ The program was run on $9^{\text {th }}$ August 2006.
} 


\begin{tabular}{|l|l|c|c|l|l|}
\hline 24 & $\mathrm{a}$ & $\mathrm{a}, \mathrm{c}, \mathrm{b}$ & $\mathrm{a}, \mathrm{c}$ & 2.00 & 3 \\
\hline 25 & $\mathrm{a}$ & $\mathrm{a}, \mathrm{c}$ & $\mathrm{a}, \mathrm{c}$ & 1.67 & 2 \\
\hline 26 & $\mathrm{a}$ & $\mathrm{a}, \mathrm{b}$ & $\mathrm{a}, \mathrm{b}, \mathrm{c}$ & 2.00 & 3 \\
\hline 27 & $\mathrm{a}$ & $\mathrm{a}, \mathrm{b}$ & $\mathrm{a}, \mathrm{b}$ & 1.67 & 2 \\
\hline 28 & $\mathrm{a}$ & $\mathrm{a}, \mathrm{b}$ & $\mathrm{a}, \mathrm{b}, \mathrm{c}$ & 2.00 & 3 \\
\hline 29 & $\mathrm{a}$ & $\mathrm{a}, \mathrm{b}$ & $\mathrm{a}, \mathrm{b}$ & 1.67 & 2 \\
\hline 30 & $\mathrm{a}$ & $\mathrm{a}, \mathrm{b}$ & $\mathrm{a}, \mathrm{b}, \mathrm{c}$ & 2.00 & 3 \\
\hline 31 & $\mathrm{a}$ & $\mathrm{a}, \mathrm{b}$ & $\mathrm{a}$ & 1.33 & 2 \\
\hline 32 & $\mathrm{a}$ & $\mathrm{a}, \mathrm{b}$ & $\mathrm{a}$ & 1.33 & 2 \\
\hline 33 & $\mathrm{a}$ & $\mathrm{a}, \mathrm{b}$ & $\mathrm{a}, \mathrm{b}$ & 1.67 & 2 \\
\hline 34 & $\mathrm{a}$ & $\mathrm{a}, \mathrm{b}$ & $\mathrm{a}, \mathrm{b}$ & 1.67 & 2 \\
\hline 35 & $\mathrm{a}$ & $\mathrm{a}, \mathrm{b}$ & $\mathrm{a}, \mathrm{b}$ & 1.67 & 2 \\
\hline 36 & $\mathrm{a}$ & $\mathrm{a}, \mathrm{b}$ & $\mathrm{a}, \mathrm{b}, \mathrm{c}$ & 2.00 & 3 \\
\hline 37 & $\mathrm{a}$ & $\mathrm{a}, \mathrm{b}$ & $\mathrm{a}$ & 1.00 & 1 \\
\hline 38 & $\mathrm{a}$ & $\mathrm{a}$ & $\mathrm{a}$ & 1.00 & 1 \\
\hline 39 & $\mathrm{a}$ & $\mathrm{a}$ & $\mathrm{a}, \mathrm{b}$ & 1.67 & 2 \\
\hline 40 & $\mathrm{a}$ & $\mathrm{a}, \mathrm{b}$ & $\mathrm{a}, \mathrm{c}$ & 1.67 & 2 \\
\hline 41 & $\mathrm{a}$ & $\mathrm{a}, \mathrm{c}$ & 1.67 & 2 \\
\hline 42 & $\mathrm{a}$ & 1.98 & 1.93 & 1.63 & 2.14 \\
\hline Average & 1.00 & & & \\
\hline
\end{tabular}

For instance, in class 1 the exponents of the morphosyntactic category $a$ (= present tense) can be deduced from the present stem, which is therefore a principal part. However, category $c$ (past participle) can be inferred from the exponents of categories $\mathbf{a}$ and $\mathbf{b}$ (preterit stem). This means that once categories $\mathbf{a}$ and $\mathbf{b}$ are known, category $\mathbf{c}$ can be deduced. Thus, an adaptive concept of class 1 requires only two principal parts to explain the entire paradigm. The fact that e.g. tun 'do' (row 1) has $u$ as the stem vowel of the present tense (category a) and /a/ as that of the past tense, automatically implies that the stem vowel of the past participle is $/ \mathrm{a} /$, as this combination is found nowhere else in the system. But for stehen 'stand' (row 2) the configuration is different. It is obvious that the present tense alone cannot predict anything, as /e/ in the present tense stem (a) is also found in a number of other classes. There are two pathways from this point. One identifies the class with the help of two principal parts, namely $\mathbf{a}$ and $\mathbf{b}(\mathbf{a}-\mathbf{a}, \mathbf{b}-\mathbf{a}, \mathbf{b})$, whereas the other uses three principal parts as in Table 3. The reason why the computer program chose the second alternative has to do with the architecture of adaptive systems explained in section 2. There are six classes of German strong verbs with /e/ as the exponent of $\mathbf{a}$, which is a principal part in all classes. Of these, three can be best identified with the help of $\mathbf{c}$, i.e. a configuration $\mathbf{a}-\mathbf{a}, \mathbf{c}-\mathbf{a}, \mathbf{c}$, for the remaining three classes the optimal set would be $\mathbf{a}-$ $\mathbf{a}, \mathbf{b}-\mathbf{a}, \mathbf{b}$. However, there can only be one common morphosyntactic category as second principal part for all classes with /e/ as an exponent of a. Usually, the program selects the path with the fewest principal parts, but in this case there is no difference: Three classes will always need two principal parts and the other three will always require two, which is why the program arbitrarily selects one of the two possibilities. This is different if $/ \varepsilon /$ is the exponent of a (see e.g. sterben 'die', row 27). The program selects $\mathbf{a} \rightarrow \mathbf{b} \rightarrow \mathbf{c}$ as path, yielding the fewest principal parts in total, though at least one class could be identified by the exponents of $\mathbf{a}$ and $\mathbf{c}$ alone.

The figures in the two columns on the right hand side in Table 3 represent the average for the relevant class as well as the actual number of principal parts needed to deduce the full paradigm; the bottom row shows how many principal parts are needed on average to deduce the relevant category and the average number of principal parts for the full paradigm across all conjugations. Hence, an adaptive conception of the strong verbs of Modern Standard German needs a minimum of one (e.g. class 9, e.g. lügen - log - gelogen 'lie', as this is the only verb with $/ y /$ as root vowel), a maximum of three (class 37, e.g. essen - a $\beta$ - gegessen 'eat', as there is at least one other class with $/ \varepsilon /$ in the present and / $\mathrm{a} /$ in the preterit, e.g. brechen - brach - gebrochen 'break') and an average of 1.63 principal parts (the actual average is 2.14). As the principal parts are not the same for each class - some just need the present stem, others all three stems - the system is skewed in terms of Finkel \& Stump (2006). It is also integrated, because sometimes two principal parts are necessary to deduce a paradigmatic form; e.g. in class 7 the past participle can be inferred from combination of the stems of the preterit and the present. Furthermore, an adaptive system of the strong verbs in Modern Standard German is 
morphologically coherent (cf. the specifications for the static version above) but non-isomorphic, because corresponding word forms in distinct paradigms are not always determined by the same principal parts.

In contrast to an adaptive model, whose tree-like hierarchical construction puts the principal parts in a linear order, a dynamic system is completely free to find parts that identify a given class anywhere in the paradigm. Hence, one class may have a variety of dynamic principal-part configurations, in which the morphosyntactic categories that constitute principal parts and the number of principal parts vary. The different possibilities of dynamic set-ups for the strong verbs of Modern Standard German calculated by the computer program can be seen in Table 4 .

Table 4: Statistics for the dynamic system

\begin{tabular}{|c|c|c|c|c|c|}
\hline Class & Principal Parts & Present stem (a) & Preterit stem (b) & Past participle (c) & $\begin{array}{l}\text { Lowest \# } \\
\text { PP }\end{array}$ \\
\hline 1 & $\begin{array}{l}\text { a,b } \\
a, c \\
b, c\end{array}$ & $\begin{array}{c}\mathrm{a} \\
\mathrm{a} \\
\mathrm{b}, \mathrm{c}\end{array}$ & $\begin{array}{c}\mathrm{b} \\
\mathrm{a}, \mathrm{c} \\
\mathrm{b}\end{array}$ & $\begin{array}{c}\mathrm{a}, \mathrm{b} \\
\mathrm{c} \\
\mathrm{c} \\
\end{array}$ & 2 \\
\hline 2 & $\begin{array}{l}a, b \\
b, c\end{array}$ & $\begin{array}{c}\mathrm{a} \\
\mathrm{b}, \mathrm{c}\end{array}$ & $\begin{array}{l}\mathrm{b} \\
\mathrm{b}\end{array}$ & $\begin{array}{c}\mathrm{a}, \mathrm{b} \\
\mathrm{c}\end{array}$ & 2 \\
\hline 3 & $\mathrm{c}$ & $\mathrm{c}$ & $\mathrm{c}$ & $\mathrm{c}$ & 1 \\
\hline 4 & $\mathrm{c}$ & $\mathrm{c}$ & $\mathrm{c}$ & $\mathrm{c}$ & 1 \\
\hline 5 & $a, b$ & $\mathrm{a}$ & $\mathrm{b}$ & $\mathrm{b}$ & 2 \\
\hline 6 & $a, b$ & $\mathrm{a}$ & $\mathrm{b}$ & $\mathrm{a}$ & 2 \\
\hline 7 & $\begin{array}{l}a, b \\
a, c\end{array}$ & $\begin{array}{l}\mathrm{a} \\
\mathrm{a}\end{array}$ & $\begin{array}{c}\mathrm{b} \\
\mathrm{a}, \mathrm{c}\end{array}$ & $\begin{array}{l}\mathrm{b} \\
\mathrm{c}\end{array}$ & 2 \\
\hline 8 & $\mathrm{a}$ & $\mathrm{a}$ & $\mathrm{a}$ & $\mathrm{a}$ & 1 \\
\hline 9 & $\mathrm{a}$ & $\mathrm{a}$ & $\mathrm{a}$ & $\mathrm{a}$ & 1 \\
\hline 10 & $\begin{array}{l}a, b \\
a, c\end{array}$ & $\begin{array}{l}\mathrm{a} \\
\mathrm{a}\end{array}$ & $\begin{array}{c}\mathrm{b} \\
\mathrm{a}, \mathrm{c}\end{array}$ & $\begin{array}{l}\mathrm{b} \\
\mathrm{c}\end{array}$ & 2 \\
\hline 11 & $a, b$ & $\mathrm{a}$ & $\mathrm{b}$ & $\mathrm{b}$ & 2 \\
\hline 12 & $a, b$ & $\mathrm{a}$ & $\mathrm{b}$ & $\mathrm{b}$ & 2 \\
\hline 13 & $\begin{array}{l}\mathrm{a}, \mathrm{b} \\
\mathrm{a}, \mathrm{c}\end{array}$ & $\begin{array}{l}\mathrm{a} \\
\mathrm{a}\end{array}$ & $\begin{array}{c}\mathrm{b} \\
\mathrm{a}, \mathrm{c}\end{array}$ & $\begin{array}{l}\mathrm{b} \\
\mathrm{c}\end{array}$ & 2 \\
\hline 14 & $a, b$ & $\mathrm{a}$ & $\mathrm{b}$ & $\mathrm{b}$ & 2 \\
\hline 15 & $\mathrm{a}$ & $\mathrm{a}$ & $\mathrm{a}$ & $\mathrm{a}$ & 1 \\
\hline 16 & $\begin{array}{l}a, b \\
a, c\end{array}$ & $\begin{array}{l}\mathrm{a} \\
\mathrm{a}\end{array}$ & $\begin{array}{c}\mathrm{b} \\
\mathrm{a}, \mathrm{c}\end{array}$ & $\begin{array}{l}\mathrm{b} \\
\mathrm{c}\end{array}$ & 2 \\
\hline 17 & $\begin{array}{l}a, b \\
b, c\end{array}$ & $\begin{array}{l}\mathrm{a} \\
\mathrm{c}\end{array}$ & $\begin{array}{l}\mathrm{b} \\
\mathrm{b}\end{array}$ & $\begin{array}{c}\mathrm{a}, \mathrm{b} \\
\mathrm{c}\end{array}$ & 2 \\
\hline 18 & $a, b$ & $\mathrm{a}$ & $\mathrm{b}$ & $a, b$ & 2 \\
\hline 19 & $\begin{array}{l}a, b \\
a, c\end{array}$ & $\begin{array}{l}\mathrm{a} \\
\mathrm{a}\end{array}$ & $\begin{array}{c}\mathrm{b} \\
\mathrm{a}, \mathrm{c}\end{array}$ & $\begin{array}{c}a, b \\
c\end{array}$ & 2 \\
\hline 20 & $\begin{array}{l}a, b \\
a, c\end{array}$ & $\begin{array}{l}\mathrm{a} \\
\mathrm{a}\end{array}$ & $\begin{array}{l}\mathrm{b} \\
\mathrm{c}\end{array}$ & $\begin{array}{c}a, b \\
c\end{array}$ & 2 \\
\hline 21 & $\mathrm{a}, \mathrm{c}$ & $\mathrm{a}$ & $\mathrm{c}$ & $\mathrm{c}$ & 2 \\
\hline 22 & $\mathrm{a}, \mathrm{c}$ & $\mathrm{a}$ & $\mathrm{c}$ & $\mathrm{c}$ & 2 \\
\hline 23 & $a, b$ & $\mathrm{a}$ & $\mathrm{b}$ & $\mathrm{a}$ & 2 \\
\hline 24 & $a, b, c$ & $\mathrm{a}$ & $\mathrm{b}$ & $\mathrm{c}$ & 3 \\
\hline 25 & $\mathrm{a}, \mathrm{c}$ & $\mathrm{a}$ & $\mathrm{a}, \mathrm{c}$ & $\mathrm{c}$ & 2 \\
\hline 26 & $a, b, c$ & $\mathrm{a}$ & $\mathrm{b}$ & $\mathrm{c}$ & 3 \\
\hline 27 & $\mathrm{~b}$ & $\mathrm{~b}$ & $\mathrm{~b}$ & $\mathrm{~b}$ & 1 \\
\hline 28 & $\mathrm{~b}, \mathrm{c}$ & $\mathrm{b}, \mathrm{c}$ & $\mathrm{b}$ & $\mathrm{c}$ & 2 \\
\hline 29 & $\begin{array}{l}a, b \\
b, c\end{array}$ & $\begin{array}{c}\mathrm{a} \\
\mathrm{b}, \mathrm{c}\end{array}$ & $\begin{array}{l}\mathrm{b} \\
\mathrm{b}\end{array}$ & $\begin{array}{c}a, b \\
c\end{array}$ & 2 \\
\hline 30 & $\mathrm{~b}, \mathrm{c}$ & $\mathrm{c}$ & $\mathrm{b}$ & $\mathrm{c}$ & 2 \\
\hline 31 & $\begin{array}{l}a, b \\
b, c\end{array}$ & $\begin{array}{c}\mathrm{a} \\
\mathrm{b}, \mathrm{c}\end{array}$ & $\begin{array}{l}\mathrm{b} \\
\mathrm{b}\end{array}$ & $\begin{array}{l}\mathrm{a} \\
\mathrm{c}\end{array}$ & 2 \\
\hline 32 & $\begin{array}{l}a, b \\
b, c\end{array}$ & $\begin{array}{c}\mathrm{a} \\
\mathrm{b}, \mathrm{c}\end{array}$ & $\begin{array}{l}\mathrm{b} \\
\mathrm{b}\end{array}$ & $\begin{array}{l}\mathrm{a} \\
\mathrm{c}\end{array}$ & 2 \\
\hline
\end{tabular}




\begin{tabular}{|l|c|c|c|c|l|}
\hline 33 & $\mathrm{a}, \mathrm{b}$ & $\mathrm{a}$ & $\mathrm{b}$ & $\mathrm{a}, \mathrm{b}$ & $\mathrm{c}$ \\
& $\mathrm{b}, \mathrm{c}$ & $\mathrm{b}, \mathrm{c}$ & $\mathrm{b}$ & $\mathrm{a}, \mathrm{b}$ & 2 \\
\hline 34 & $\mathrm{a}, \mathrm{b}$ & $\mathrm{a}$ & $\mathrm{b}$ & $\mathrm{a}, \mathrm{b}$ & \\
\hline 35 & $\mathrm{a}, \mathrm{b}$ & $\mathrm{a}$ & $\mathrm{b}$ & $\mathrm{c}$ & 2 \\
& $\mathrm{~b}, \mathrm{c}$ & $\mathrm{b}, \mathrm{c}$ & $\mathrm{c}$ & $\mathrm{c}$ & 2 \\
\hline 36 & $\mathrm{a}, \mathrm{c}$ & $\mathrm{a}$ & $\mathrm{c}$ & $\mathrm{a}$ & 1 \\
\hline 37 & $\mathrm{a}, \mathrm{c}$ & $\mathrm{a}$ & $\mathrm{a}$ & $\mathrm{a}$ & 1 \\
\hline 38 & $\mathrm{a}$ & $\mathrm{a}$ & $\mathrm{a}$ & $\mathrm{c}$ & 1 \\
\hline 39 & $\mathrm{a}$ & $\mathrm{a}$ & $\mathrm{c}$ & $\mathrm{c}$ & 1 \\
\hline 40 & $\mathrm{c}$ & $\mathrm{c}$ & $\mathrm{c}$ & $\mathrm{c}$ & 1 \\
\hline 41 & $\mathrm{c}$ & $\mathrm{c}$ & $\mathrm{c}$ & 1.18 & 1.78 \\
\hline 42 & $\mathrm{c}$ & $\mathrm{c}$ & 1.16 & 1.12 & \\
\hline Average & 1.84 & & & & \\
\hline
\end{tabular}

The second column on the left, entitled Principal Parts, shows the morphosyntactic categories that constitute principal parts for a given class under different dynamic configurations. The next three columns display how the different morphosyntactic categories are explained by the assumed principal parts, and the last column contains the lowest number of principal parts needed for a conjugation class, since one of the requirements concerning the optimality of a principal-parts system is that the set of principal parts is minimal (cf. section 2 above).

Hence, under a dynamic concept the number of principal parts required for the strong verbs of Modern Standard German ranges between one and three, with an average of 1.78, always based on the lowest number of principal parts per class. Note also that nearly all the exponents of a given morphosyntactic category are deducible from just one dynamic principal part (see average figures in columns two, three and four in the bottom row). Of course, the system is skewed, as it is apparent that the principal parts are not the same for each conjugation class. The fact that in some cases the exponents of a morphosyntactic category can only be deduced from a combination of the relevant principal parts means that the system is integrated. In addition, like the adaptive version, a dynamic model of the strong verbs is morphologically coherent and non-isomorphic.

\subsection{A comparative interpretation of the three analyses}

This section compares the three different principal-parts analyses in terms of adequacy and complexity. Table 5 shows the key characteristics of the static, the adaptive and the dynamic system.

Table 5: Comparative interpretation

\begin{tabular}{|l|l|l|l|l|l|l|}
\hline SYSTEM & $\#_{\text {MAX. }}$ PP & $\#_{\text {AVER. }}$ PP & CRITERION B & CRITERION C & CRITERION D & CRITERION E \\
\hline Static & 3 & 3 & parallel & segregated & coherent & isomorphic \\
\hline Adaptive & 3 & 2.14 & skewed & integrated & coherent & non-isom. \\
\hline Dynamic & 3 & 1.78 & skewed & integrated & coherent & non-isom. \\
\hline
\end{tabular}

In terms of optimality as defined by Finkel \& Stump (2006) the dynamic system is clearly the optimal approach, as it is both minimal and adequate..$^{33}$ It is, however, less clear what this means in terms of learnability and complexity, because, at least intuitively, this seems to have an impact on the overall adequacy of the selected model. The prediction by Finkel \& Stump (2006) that static systems tend to have more principal parts than adaptive and dynamic ones is not borne out in absolute terms, but from a comparison of Tables 2, 3 and 4 it becomes clear that under the more flexible models a considerable number of conjugation classes can be identified using less than three principal parts. However, it has to be noted that despite having fewer principal parts, both the adaptive and the dynamic approaches are far less predictable, because the principal parts and their combinations in the prediction of exponents keep changing from one class to the other. Although the flexibility of these systems helps to bring down the number of principal parts, which is likely to facilitate the learning process, the lack of

\footnotetext{
${ }^{33}$ Finkel \& Stump (2006:3-4) argue that optimality in adaptive and dynamic systems really has to be determined for every class. However, assuming that in every class the set with the lowest number of principal parts is chosen, both approaches are always minimal and adequate. Of course, the number of principal parts may vary from one class to another, but the average number of principal parts that is calculated permits a comparison between static and adaptive/dynamic systems.
} 
predictability is at the same time a considerable obstacle to the learning process. This is why static systems are generally less complex than adaptive and dynamic ones. If the complexity correlations in (4) above are used in the comparison of the three systems, it becomes clear that the static system in Table 5 is the least complex. According to (4a) static systems are generally the least complex, (4c) states that segregated systems are simpler than integrated ones, (4d) holds that morphologically coherent systems are less complex than incoherent ones and (4e) asserts that isomorphic systems are simpler than non-isomorphic systems. These considerations seem to outweigh the argument that the static version has always more principal parts, namely three, than the more flexible models, especially since those systems actually need a maximum of three principal parts too. Nevertheless, the actual number of verbs that can be explained with one principal part under the dynamic system (e.g. classes 3, 4 and 27, which belong to well-supported classes, cf. Table 2) is remarkable. As a result of these considerations, the static system actually seems to be the most learner-friendly conceptualisation of the Modern German strong verbs, because it is parallel and the number of principal parts is in the majority of cases not higher than in the two other systems. This suggests that adaptive and dynamic conceptualisations of the strong verbs in Modern German are of primarily theoretical interest, but neither seem to be pedagogically useful, nor appear to reflect the psychological reality. ${ }^{34}$

Moreover, as Albright (2002) and Albright and Hayes (2003) show, many inflectional rules have phonological domains where they are especially strong, i.e. reliable. The basis for different minimal generalisations among the strong verbs has grown considerably in the last two millennia, making individual classes especially tight. Thus, in some cases like class 30, e.g. finden 'find', sinken 'sink' etc., speakers would probably not think of forming a regular paradigm for a matching nonsense input, because the rule predicting a strong inflection is very reliable, it is an "island of reliability" (see also Albright and Hayes 2003). ${ }^{35}$ As a result, speakers of German appear to have an intuitive notion of the strong verbs as a group, though in reality they only follow very reliable rules extracted from subgeneralisations based on phonological root structure. However, it is also clear that despite the availability of islands of reliability, the strong verbs of Modern German - in contrast to those of Middle High German and earlier stages - have lost the unambiguous identification of the conjugation class on the basis of phonological root structure. For instance, verbs with $i+$ nasal can either in class 28 , e.g. schwimmen 'swim' and spinnen 'spin' or in class 14, e.g. klimmen 'climb'. This is the reason why only the ablaut change was considered in the principal-parts analysis.

What this discussion has shown is that the strong verbs of Modern Standard German as a group may in parts be stronger than is often assumed, held together by a system based on a highly efficient mechanism of minimal generalisations, i.e. the creation of very specific rules. But it has also become clear that for some classes the islands of reliability have become rather small, which means they effectively have to be stored as irregular verbs, with their root structure acting as a possible hint towards the strong inflection. Their inclusion in the system of the strong verbs follows from the considerations presented in section 5.3. The principal part analysis demonstrates that the strong verbs of Modern German form a system that may at least partly be described more elegantly under a more flexible approach than under the traditional static model. However, from the viewpoint of the language learner, the static conceptualisation is by far the most useful, due to the high predictability of its principal parts. ${ }^{36}$

\section{Comparative analysis and Conclusion}

\footnotetext{
${ }^{34}$ Thanks go to Jennifer Hay (p.c.) for pointing this additional conclusion out to me.

${ }^{35}$ Likewise, the case of *gehissen, cited above, instead of regular geheißen after the model of reißen - gerissen and not 'regular' *geheißt suggests that speakers exploit the capabilities of minimal generalisations before the default is applied.

${ }^{36}$ From the viewpoint of language change it seems unusual that both sound change and analogy should have increased the system's complexity, as Adam Albright (p.c.) points out. He wonders whether analogical change from Middle High German to Modern German might have to some degree the effect of reducing the complexity of the system by decreasing the number of principal parts or by permitting a more precise prediction of class membership. There is indeed a great deal of simplifying effect of analogy from Middle High German to Modern German, but this occurs intra-paradigmatically rather than on a systemic level. This means that while the system becomes more fragmented, individual paradigms are simplified, as paradigmatic differences in stem and affixes are levelled. Thus, the system as a whole, in particular the prediction of class membership, has become more complicated, but the paradigms have been streamlined considerably.
} 
This concluding section compares the system of the strong verbs in its earliest tangible shape, i.e. in Proto-Germanic, with that in its current shape, i.e. Modern Standard German, from the viewpoint of the principal-parts model. The aim is to highlight common and dividing features in order to pinpoint exactly what has changed over the last two thousand years. From the investigation of the diachronic development, the most decisive changes seem to be the fragmentation of the system as well as the fact that an ablaut pattern can no longer be unambiguously identified through the phonological structure of the stem of the citation form, i.e. the present stem. The question is whether this prediction will be borne out by the comparative analysis of the principal part analyses. Table 6 shows the different analyses for the strong verbs of Modern German and those of Proto-Germanic.

Table 6: Comparative Analysis

\begin{tabular}{|l|c|l|l|l|l|l|l|}
\hline SYSTEM & CLASSES & $\begin{array}{l}\#_{\text {MAX. }} \\
\text { PP }\end{array}$ & $\begin{array}{l}\#_{\text {AVER. }} \\
\text { PP }\end{array}$ & $\begin{array}{l}\text { CRITERION } \\
\text { B }\end{array}$ & $\begin{array}{l}\text { CRITERION } \\
\text { C }\end{array}$ & $\begin{array}{l}\text { CRITERION } \\
\text { D }\end{array}$ & $\begin{array}{l}\text { CRITERION } \\
\text { E }\end{array}$ \\
\hline PGmc. & 8 & 1 & 1 & parallel & segregated & coherent & isomorphic \\
\hline $\begin{array}{l}\text { Mod. St. G. } \\
\text { static }\end{array}$ & 42 & 3 & 3 & parallel & segregated & coherent & isomorphic \\
\hline adaptive & 42 & 3 & 2.14 & skewed & integrated & coherent & non-isom. \\
\hline dynamic & 42 & 3 & 1.78 & skewed & integrated & coherent & non-isom. \\
\hline
\end{tabular}

As can be seen from Table 6, the predictions are by and large confirmed. Under a static model the only differences seem to be that Proto-Germanic has fewer principal parts and fewer classes. An adaptive/dynamic approach brings down the average number of principal parts, but makes the system more difficult to use, because the principal parts have to be memorised for each class. However, the most striking point is that the only principal part in Proto-Germanic is the citation form. In addition, the Proto-Germanic system uses minimal generalisation based on phonological root structure to predict class membership via context-specific rules. Hence, all verbs with a given root structure belong to the same conjugation class. Moreover, the stems of any ablauting paradigm are formed by insertion of a pre-defined pattern of vowels, the ablaut pattern. As a result, the strong verbs of Proto-Germanic are organised into a very simple and efficient system that can be easily acquired. Consequently, the key difference between the strong verbs of Proto-Germanic and those of Modern Standard German is the fact that class membership and the ablaut pattern can no longer be predicted, they largely have to be memorised. However, where remnants of the old class allocation systems are still intact, i.e. in better supported classes, the strong verbs form an effective conjugation that follows highly reliable rules. ${ }^{37}$ Moreover, the functional value of ablaut has actually increased (see also Wiese forthc.), because a number of paradigmatic forms are differentiated only by ablaut, whereas in Proto-Germanic ablaut is only distinctive for verbal stems.

To sum up, this paper aimed at a diachronic investigation comparing the strong verbs of ProtoGermanic and Modern Standard German using the principal-part analysis proposed by Finkel \& Stump (2006). Its aim was to bring out the key points of the different systems and their development over roughly two millennia. The analysis conducted confirms that the biggest differences between the organisation of the strong verbs of Proto-Germanic and those of Modern Standard German are that the number of principal parts as well as the number of classes have increased sharply and that class membership is no longer based on the phonological root structure of the citation form, instead it has to be memorised. ${ }^{38}$ However, the strategy of minimal generalisation allows the creation of "islands of reliability", which is practicable precisely for those classes for which the root structure still allows a

\footnotetext{
${ }^{37}$ This is not in disagreement with Wiese (forthc.), who says that the synchronic regularities are not merely remnants of a "once well-behaved system". Needless to say, the regularities of the ablaut formations in the Modern German strong verbs may be described differently, but that there are quite stable and operational remnants of the Proto-Germanic system is undeniable.

${ }^{38}$ This is in disagreement with Wiese (forthc.), who claims that class membership is highly predictable. However, the assignment rules given by Wiese (forthc.) seem rather abstract. They mainly involve the ablauting vowel and the distribution of different ablaut grades within the paradigm, and Wiese (forthc.) tacitly admits that his rules have an inherent degree of uncertainty: "Usually, there are two or at most three classes that have to be taken into account". In addition, Wiese's (forthc.) predictions do not match the results in Bybee \& Slobin (1982), Albright (2002), Albright \& Hayes (2003) and Kieferle \& Lindner (2003). All four studies show that minimal generalisations are formed on the basis on the phonological root structure of the citation form, and not on a verb's ablaut pattern.
} 
rather reliable prediction of class membership. This legacy of the original system is the strength of the strong verbs in Modern Standard German and can explain why they have survived over two millennia with an "almost scandalous tenacity" as what may be called an island of resilience. (Vennemann 1998a: 41, n.72, translating the classic quotation by Szemerényi 1990:89, "mit fast unerhörter Zähigkeit”).

\section{References:}

Albright, A. (2002). Islands of reliability for regular morphology: Evidence from Italian. Language, 78(4), 684709.

Albright, A., Hayes, B. (2002). Modeling English past tense intuitions with minimal generalization. In Proceedings of the ACL 2002 Workshop on Morphological and Phonological Learning. ACL Publications.

Albright, A., Hayes, B. (2003). Rules vs. analogy in English past tenses: a computational/experimental study. Cognition, 90, 119-161

Augst, G. (1975). Wie stark sind die starken Verben?. In G. Augst (Ed.), Untersuchungen zum Morpheminventar der deutschen Gegenwartssprache (pp. 231-281), Tübingen: Narr.

Bammesberger, A. (1986). Das germanische Verbalsystem. Heidelberg: Winter.

Becker, T. (1990). Analogie und morphologische Theorie. München: Fink.

Becker, T. (1998). Das Vokalsystem der deutschen Standardsprache. Bern: Peter Lang.

Bittner, Andreas (1996). Starke, schwache'Verben, schwache, starke' Verben. Deutsche Verbflexion und Natürlichkeit. Tübingen: Stauffenburg.

Blevins, J. (2003). Stems and Paradigms. Language, 79(4), 737-767.

Braune, W. \& Reiffenstein, I. (2004). Althochdeutsche Grammatik I. 15th ed. by I. Reiffenstein. Tübingen: Niemeyer.

Bybee, J. \& Slobin D. (1982). Rules and Schemas in the Development and Use of the English past tense. Language, 58(2), 265-289.

Clahsen, H., Eisenbeiss, S. \& Sonnenstuhl-Henning, I. (1997). Morphological structure and the processing of inflected words. Theoretical Linguistics, 23(3), 225-55.

Coetsem, F. van (1990). Ablaut and Reduplication in the Germanic verb. Heidelberg: Winter.

Dreyer, Hilke, Schmitt Richard (2002). Lehr- und Übungsbuch der deutschen Grammatik. Ismaning: Hueber [reprint from 1st ed. 1999].

Duden (1998). Die Grammatik. $6^{\text {th }}$ ed. Mannheim: Dudenverlag.

Duden (2005), Die Grammatik. $7^{\text {th }}$ ed. Mannheim: Dudenverlag.

Eisenberg, P. (2004). Grundriß der deutschen Grammatik. Band 1 Das Wort. 2nd ed. Stuttgart: Metzler.

Finkel, R. \& Stump, G. (2006). Principal parts and morphological typology", Ms. Technical Report No. 459-06. Department of Computer Science, University of Kentucky [ftp://ftp.cs.uky.edu/cs/techreports/459-06.pdf].

Gafos, A. I. (2003). Greenberg's asymmetry in Arabic: A consequence of stems in Paradigms. Language, 79(2), 317-355.

Helbig, G. \& Buscha, J. (2005). Deutsche Grammatik. Berlin/Munich: Langenscheidt.

Hempen, U. (1988). Die starken Verben im Deutschen und Niederländischen. Tübingen: Niemeyer.

Kern, P. \& Zutt, H. (1977). Geschichte des deutschen Flexionssystems. Tübingen: Niemeyer.

Kieferle, C. \& Lindner, K. (2003). Gehte or gang? What do children in third and fourth grade know about past tense forms and participles of strong and weak verbs?. Paper presented at the $25^{\text {th }}$ Annual Meeting of the German Society for Linguistics, Munich, $26^{\text {th }}-28^{\text {th }}$ February 2003.

Köpcke, K.-M. (1998). Prototypisch starke und schwache Verben der deutschen Gegenwartssprache. Germanistische Linguistik, 141-142, 45-59.

Kortlandt, F. (1992). The Germanic Fifth Class of Strong Verbs. North Western Language Evolution, 19, 27-81

Mailhammer, R. (2006). On the Origin of the Germanic Strong Verb System. Sprachwissenschaft, 31(1), 1-52.

Mailhammer, R. (2007). The Germanic Strong Verbs: Foundations and Development of a New System. Berlin/New York: Mouton de Gruyter.

Mailhammer, R. (in press). The Typological Significance of Ablaut in the Prehistory of English. In Th. Honegger and W. Rudolf (eds.), Clerks, Wives, and Historians: Essays on Medieval English Literature, Bern: Peter Lang.

Meier-Brügger, M. (2002). Indogermanische Sprachwissenschaft. $8^{\text {th }}$ ed. Berlin/New York: de Gruyter.

Mel'čuk, I. A. (1976). Zur 'inneren Flexion' in den indoeuropäischen und semitischen Sprachen. In I. A. Mel'čuk, Das Wort. Zwischen Inhalt und Ausdruck (pp. 258-287). Munich: Fink.

Newfield, M. (1981). The Disintegration of Germanic Verbal Ablaut in Old English. Orbis, 30, 114-134.

Nübling, D. (2000a). Prinzipien der Irregularisierung. Eine kontrastive Analyse von zehn Verben in zehn germanischen Sprachen. Tübingen: Niemeyer.

Nübling, D. (2000b). Entwicklungen im Flexionsklassen- und Ablautsystem des Alemannischen. In E. Funk et 
al. (Eds.), Bausteine zur Sprachgeschichte (217-229) Heidelberg: Winter.

Pinker, St. \& Prince, A. (1988). On language and connectionism: Analysis of a parallel distributed processing model of language acquisition. Cognition, 28, 73-193.

Raffelsiefen, R. (2002). Imperatives: the relation between meaning and form. In D. Restle and D. Zaefferer (eds.), Sounds and Systems. Studies in Structure and Change. Festschrift for Theo Vennemann (pp. 321347). Berlin/New York: Mouton De Gruyter.

Reichmann, O. \& Ebert, R. P. (1993). Frühneuhochdeutsche Grammatik. Tübingen: Niemeyer.

Restle, D. (2003). Silbenschnitt - Quantität - Kopplung. Munich: Fink.

Rhee, F. van der (1973). Vokalalternanzen im germanischen starken Verbum. Amsterdamer Beiträge zur älteren Germanistik, 5, 11-31.

Ringe, D. (2006). From Proto-Indo-European to Proto-Germanic. A Linguistic History of English Volume 1. Oxford: Oxford University Press.

Rubba, J. (2001). Introflexion. In M. Haspelmath et al. (Eds.), Language Typology and Language Universals (pp. 678-694). Berlin/New York: de Gruyter.

Ruoff, A. (1981). Häufigkeitswörterbuch gesprochener Sprache. Tübingen: Niemeyer.

Scheer, T. (1998). A Generalised Theroy of Ablaut: the case of Modern German Strong Verbs. In R. Fabri, A. Ortmann and T. Parodi (eds.), Models of Inflection. Tübingen: Niemeyer.

Seebold, E. (1970). Vergleichendes und etymologisches Wörterbuch der germanischen starken Verben. The Hague: Mouton.

Szemerényi, O. (1990). Einführung in die vergleichende Sprachwissenschaft. $4^{\text {th }}$ ed. Darmstadt: Wissenschaftliche Buchgesellschaft.

Tichy, E. (2004). Indogermanistisches Grundwissen, $2^{\text {nd }}$ ed., Bremen: Hempen

Vennemann, Th. (1991). Syllable cut prosodies in Modern Standard German. In Pier Marco Bertinetto, Michael Kenstowicz and Michele Loporcaro (eds.), Certamen Philologicum 2 (pp. 211-43). Turin: Rosenberg \&

Sellier.

Vennemann, Th. (1994). Zur Entwicklung der reduplizierenden Verben im Germanischen. Beiträge zur Geschichte der deutschen Sprache und Literatur, 116, 167-221.

Vennemann, Th. (1997). The development of reduplicating verbs in Germanic. In I. Rauch \& G. F. Carr (Eds.), Insights in Germanic Linguistics II Classic and Contemporary (pp. 297-336). Berlin/New York: de Gruyter.

Vennemann, Th. (2000). Zur Entstehung des Germanischen. Sprachwissenschaft, 25(3), 233-269.

Voyles, J. B. (1992). Early Germanic Grammar. San Diego: Acad. Press.

Wiese, B. (forthc.). Form and function of verbal ablaut in Contemporary Standard German. In R. Sackmann (Ed.), Studies in Integrational Linguistics. Amsterdam/Philadelphia: Benjamins [http://www.idsmannheim.de/gra/texte/wi2.pdf].

Wurzel. W. U. (1989). Inflectional morphology and naturalness. Transl. by M. Schentke. Dordrecht: Kluwe. 


\section{University Library}

\section{- M M I N E R VA A gateway to Melbourne's research publications}

Minerva Access is the Institutional Repository of The University of Melbourne

Author/s:

Mailhammer, $\mathrm{R}$

Title:

Islands of resilience: the history of the German strong verbs from a systemic point of view

Date:

2007-11-27

Citation:

Mailhammer, R. (2007). Islands of resilience: the history of the German strong verbs from a systemic point of view. Morphology, 17 (1), pp.77-108. https://doi.org/10.1007/ s11525-007-9113-y.

Publication Status:

Published

Persistent Link:

http://hdl.handle.net/11343/34891 